\title{
Old English <cg> and its sound correspondences in Old English and Middle English
}

\author{
Gjertrud F. Stenbrenden, University of Oslo
}

\section{Introduction ${ }^{1}$}

Most elementary grammars of Old English (OE), as well as textbooks on the history of English, state that the digraph $\langle\mathrm{cg}\rangle$ was pronounced as [d]], that is, a voiced post-alveolar affricate (Sweet/Davis 1983: 4; Quirk \& Wrenn 1989: 16; Mitchell \& Robinson 1992: 16). Even the reference grammars, however, provide little evidence in support of this claim, beyond (a) a few seeming cases of affrication across $\mathrm{OE}$ morpheme boundaries (so, e.g. micgern 'fat' from *mid+gern, cf. orceard 'orchard' from *ort+geard), and (b) the reflex of this segment as [d3] in Present-Day English (PDE): so, for example, Campbell (1959: 173-179), Wright \& Wright (1982: 167), Sievers (1968: 143-155). Rather, the assumed development of [d3] in OE, along with that of its voiceless counterpart [t $\mathrm{t}]$, is presented as an outcome of the Anglo-Frisian palatalisations of $[\mathrm{k}]$ and $[\mathrm{g}]$ in contact with front vowels: this makes it cohere with a larger chapter in the history of OE phonology, on which it then seems to depend. Otherwise, the topic looks to have attracted little further attention, with the exceptions of Welna (1986) and Minkova (2003, 2014, 2016, 2019).

Nevertheless, in its own terms the OE digraph $\langle\mathrm{cg}\rangle$ seems remarkably ill-suited as the correspondent of a sound-segment [dz]. OE $\langle\mathrm{c}\rangle$ usually corresponds to [k] or its palatalised reflex $[\mathrm{t} f] /[\mathrm{c}]^{2}$ (as well as, though mainly in early Old Northumbrian in absolute final position in unstressed words, the fricatives $[\mathrm{c}]$ and $[\mathrm{x}]$ ), whereas $\mathrm{OE}\langle\mathrm{g}\rangle$ corresponds to $[\gamma]$ or its palatalised reflex [j], or to [g] or its palatalised reflex [f] (at first only in combination with [y]). The digraph $\langle\mathrm{cg}>$ thus appears to represent a cluster consisting of a voiceless velar or palatal consonant followed by a voiced velar or palatal consonant. The sequence \{voiceless+voiced is hence supposed to represent the \{voiced+voiced $\}$ sequence of [d]], with no trace, moreover, of the affricate's palatoalveolar onset.

Ladefoged \& Maddieson (1996: 90) define affricates as "stops in which the release of the constriction is modified in such a way as to produce a more prolonged period of frication after the release". Affricates are thus typically homorganic and are seen as one segment; examples are $[\mathrm{pf}, \mathrm{ts}, \mathrm{d} 3, \mathrm{kx}]$. I will use the term 'phonetic affricate' to refer to any realisation that fits the above definition, and the term 'phonemic affricate' to refer to a (phonetic) affricate which is distinctive in a given language.

The primary aim of the present article is to argue that $\mathrm{OE}\langle\mathrm{cg}>$ did not correspond to [d3], that there is no evidence for a phonetic or phonemic affricate until late Middle English (ME), and that there are better candidates than [dz] for the sound correspondence of $\mathrm{OE}\langle\mathrm{cg}\rangle$ and which

\footnotetext{
${ }^{1}$ Early versions of this article were read at the $52^{\text {nd }}$ International Congress on Medieval Studies (Western Michigan University, 11-14 May, 2017) and the $10^{\text {th }}$ International Conference on Middle English (University of Stavanger, 31 May-2 June, 2017). I wish to thank members of the audience for useful feedback. I am also grateful to Michael Benskin, Donka Minkova, Patrick Stiles, the two anonymous reviewers and the editor for reading draft versions of this paper and for providing numerous insightful comments and suggestions for improvement. The remaining shortcomings, and views, are entirely my own responsibility.

${ }^{2}$ That the OE reflex of palatalised $k$ may have been [c] or [ç] rather than [t]] is the author's personal view and is based on the absence of $\langle\mathrm{t}-\rangle$ in the relevant lexis in the $\mathrm{OE}$ corpus. It is not a widely held opinion, but Minkova (2014: 81-82) entertains similar views; she suggests $\left[\mathrm{c} / \mathrm{k}^{\mathrm{j}}\right]$ for palatalised $k$ in classical OE. See further the discussion in section 2 .
} 
are bisegmental. My findings thus support Minkova's main arguments regarding the development of affricates in English (2003, 2016, 2019), although my conclusions were arrived at independently, were drawn from a very different set of data, and take Minkova's conclusions one step further. ${ }^{3}$

The Present-Day English (PDE) reflexes of OE words with $\langle\mathrm{cg}\rangle$ testify to two diverging historical developments: (a)/dz/ in nouns like edge, bridge, ridge (OE ecg, brycg, hrycg), or (b) /eI/ or /ai/ in the verbs say, lay, lie, buy (OE secgan, lecgan, licgan, bycgan). The second aim of my paper is to determine when and where the diverging developments began.

Until recently, the evidence adduced for the sound correspondence of $\mathrm{OE}\langle\mathrm{cg}\rangle$ has been of two kinds: comparative evidence from the prehistory of $\mathrm{OE}\langle\mathrm{cg}\rangle$ words in other early Germanic $(\mathrm{Gmc})$ languages, and spellings co-variant with $\langle\mathrm{cg}\rangle$ in $\mathrm{OE}$ texts. To the latter group belongs evidence pertaining to the development to $/ \mathrm{d} z /$ of consonant clusters in words which do not belong etymologically to the $\mathrm{OE}<\mathrm{cg}>$ words, e.g. micgern, singe 'to burn lightly'. Additionally, ME spelling evidence has been used to argue for the terminal value [d3] in ME, but has not hitherto been used to shed light on the likely OE sound correspondence(s) of $\langle\mathrm{cg}\rangle$.

With the publication of LAEME (Laing 2008), there is now a substantial body of spelling material for early ME, which may be used to infer much about the phonology of early English. The present article seeks to re-examine the available evidence for the sound correspondence of $\mathrm{OE}<\mathrm{cg}>$ and to offer a new interpretation as to the likely pronunciation of $\mathrm{OE}<\mathrm{cg}>$. I examine some 1500 spellings for $\mathrm{OE}<\mathrm{cg}>$ words in $L A E M E$, with a view to answering the following questions: (1) Are the ME spellings consistent enough, lexically and diachronically, or in individual texts, for any patterns to be detected? (2) If so, is it possible to establish the likely $\mathrm{OE}$ and ME sound correspondences of $\langle\mathrm{cg}\rangle$ ? (3) Had the diverging developments of nouns and verbs started in the period investigated? (4) To what extent did the sound development of OE $<\mathrm{cg}>$ depend on word-class, analogy, paradigmatic levelling, and position within the word?

Section 2 examines the prehistory of $\mathrm{OE}<\mathrm{cg}>$ words in an attempt to determine the sound cognates of $\langle\mathrm{cg}\rangle$ in the other early Gmc languages. Section 3 gives a summary of the suggested path(s) of change from Gmc *-gj- to PDE /dz/ as offered by previous scholars. Section 4 presents and discusses the spellings for $\mathrm{OE}<\mathrm{cg}>$ in $L A E M E$. I offer my suggestion for the sound correspondence of $\mathrm{OE}<\mathrm{cg}>$ in section 5, and I outline the path of change to PDE /dz/ in section 6. Section 7 gives a summary of the findings of this article.

\section{The etymology of $\mathrm{OE}<\mathrm{cg}>$ words in PGmc}

The inferred Proto-Germanic (PGmc) forms of words with $\mathrm{OE}\langle\mathrm{cg}\rangle$ seem relatively certain: the cluster goes back to PGmc *-gj-(OED Online), and the sound value was probably [gj] or [j]] (where [J] is the IPA symbol for the voiced palatal stop; [c] is the IPA symbol for the corresponding voiceless palatal stop). I shall refer to words which have reflexes of Gmc *gj, and which appear with $\mathrm{OE}<\mathrm{cg}>$, as ' $<\mathrm{cg}>$ words'. Tables 1 and 2 show the spellings of the cognates of some of the most common OE $<\mathrm{cg}>$ words in the other early Gmc languages, as well as their later developments (in italics).

\footnotetext{
${ }^{3}$ Minkova's articles $(2016,2019)$ were brought to my attention late in the process of writing this paper.
} 
Table 1. Gmc cognates and PDE reflexes of OE nouns with $\langle\mathrm{cg}\rangle \mathbf{4}$

\begin{tabular}{|c|c|c|c|c|c|c|c|}
\hline OE & $\begin{array}{l}\text { brycg } \\
\text { 'bridge' }\end{array}$ & $\begin{array}{l}\text { ecg } \\
\text { 'edge' }\end{array}$ & $\begin{array}{l}\text { hrycg } \\
\text { 'ridge' }\end{array}$ & $\begin{array}{l}\text { mycg } \\
\text { 'midge' }\end{array}$ & $\begin{array}{l}\text { secg I }{ }^{1} \\
\text { 'man, hero' }\end{array}$ & $\begin{array}{l}\text { secg II }{ }^{2} \\
\text { 'sedge' }\end{array}$ & $\begin{array}{l}\text { wecg } \\
\text { 'wedge' }\end{array}$ \\
\hline $\mathrm{PGmc}^{5}$ & *brugjō/â & *agjō & *hrugjaz & *mugjō & $*_{\text {sagjaz }}$ & *sagj- & *wagj- \\
\hline Gothic & & & & & *sagj- & & \\
\hline O Fris & brigge & egg, edze & hregg & & siā & & \\
\hline $\mathrm{O} \mathrm{Du}$ & & & $\begin{array}{l}\text { ruggi, } \\
\text { rukgi }\end{array}$ & & & & \\
\hline$M D u$ & brugghe & egghe & $\begin{array}{l}\text { rugge, } \\
\text { rucke }\end{array}$ & $\begin{array}{l}\text { mugghe, } \\
\text { mucke }\end{array}$ & & & $\begin{array}{l}\text { wegge, } \\
\text { wigge }\end{array}$ \\
\hline Dutch & brug & egge & rug & mug & & zegge & wegge \\
\hline OS & bruggia & eggia & hruggi- & muggia & segg & & weggi \\
\hline$M L G$ & brugge & & $\begin{array}{l}\text { rügge, } \\
\text { ruckge }\end{array}$ & mugge & & segge & $\begin{array}{l}\text { wegge, } \\
\text { wigge }\end{array}$ \\
\hline$\overline{\mathrm{OHG}}$ & brucca & $\begin{array}{l}\text { egga, } \\
\text { ekka }\end{array}$ & $\begin{array}{l}\text { hruggi, } \\
\text { hrucki }\end{array}$ & $\begin{array}{l}\text { mucca, } \\
\text { mugga }\end{array}$ & & sahor & $\begin{array}{l}\text { weggi, } \\
\text { wecki }\end{array}$ \\
\hline German & Brücke & Ecke & Rücken & Mücke & & Saher & Weck \\
\hline $\mathrm{ON}^{6}$ & bryggja & egg & hryggr & mȳ & seggr & & veggr \\
\hline Norwegian & brygg(j)e & $e g g$ & rygg & mygg & segg & & vegg \\
\hline Swedish & brygga & egg & rygg & mygga & & & vigg \\
\hline Danish & & & ryg & myg & & & vagge \\
\hline
\end{tabular}

${ }^{1}$ OE secg I: 'man, warrior, hero'. ${ }^{2}$ OE secg II: 'sedge'.

Table 2. The Gmc cognates and present-day reflexes of $\mathrm{OE}$ verbs with <cg $>$

\begin{tabular}{|l|l|l|l|l|l|l|}
\hline OE & $\begin{array}{l}\text { bycgan } \\
\text { 'buy' }\end{array}$ & $\begin{array}{l}\text { hycgan } \\
\text { 'think' }\end{array}$ & $\begin{array}{l}\text { lecgan } \\
\text { 'lay' }\end{array}$ & $\begin{array}{l}\text { licgan } \\
\text { 'lie' }\end{array}$ & $\begin{array}{l}\text { secgan } \\
\text { 'say' }\end{array}$ & $\begin{array}{l}\text { picgan } \\
\text { 'receive' }\end{array}$ \\
\hline PGmc & *bugjana & *hugjana & *lagjana & *ligjana & *sagjana & *pigjana \\
\hline Gothic & bugjan & hugjan & lagjan & ligan & & \\
\hline O Fris & & & ledza, lega, leia & lidzia & $\begin{array}{l}\text { sedza, sega } \\
\text { WFr sizze }\end{array}$ & \\
\hline Dutch & & & ODu leggen & & zeggen & \\
\hline OS & buggian & huggian & leggian & liggian & $\begin{array}{l}\text { seggian } \\
\text { LG seggen }\end{array}$ & thiggian \\
\hline OHG & & hucken & $\begin{array}{l}\text { legen, } \\
\text { lecken }\end{array}$ & liggen & sagēn & $\begin{array}{l}\text { dikken } \\
\text { MHG digen }\end{array}$ \\
\hline German & & & legen & & sagen & \\
\hline ON & byggja & huga, hyggja & leggja & liggja & segja & piggja \\
\hline Norw. & bygge & hugsa, huske & legg(j)e & ligg(j)e & si(ge), seie & tigg(j)e \\
\hline Swedish & & & lägga & ligga & säga & tigga \\
\hline Danish & & & laggge & ligge & sige & tigge \\
\hline
\end{tabular}

It seems quite clear that $\langle\mathrm{cg}\rangle$ goes back to a geminated $* g$ before $* j$ in WGmc (West-Gmc Gemination, cf. Campbell 1959: $§ 407$; Stiles 2013: 15 ); the $* j$ was subsequently lost, but not

\footnotetext{
${ }^{4} \mathrm{Du}=$ Dutch; Fris = Frisian; OS = Old Saxon LG = Low German; OHG = Old High German; MHG = Middle High German; ON = Old Norse. The spellings are taken from the OED Online and from Laker (2007).

${ }^{5}$ There is disagreement over the last vowel of the reconstructed PGmc forms, but that is not relevant here. HEDGE $(<\mathrm{PGmc} *$ hagjo $)$ in all likelihood belongs to this group of words also.

${ }^{6}$ The NGmc forms are included for comparison: the same words that undergo gemination in WGmc, and which are the topic of investigation here, undergo other processes in NGmc, producing similar consonant clusters. The same applies to the NGmc forms in Table 3.
} 
before it had caused the palatalisation of the preceding velar stops in OE and Old Frisian. ${ }^{7}$ Hence, the values $[\mathrm{gg}(\mathrm{j})]$ and $[\mathrm{JJ}(\mathrm{j})]$ seem probable in the early WGmc languages.

The Gmc velar stops $* k$ and $* g$ palatalised before front vowels in Pre-OE and in Old Frisian (Campbell 1959: $\S \S 426-430) .{ }^{8}$ The precise development of the palatalised singletons may have been as in (1). The values [t $[$ ] and [j] are assumed for Old English by most textbooks, although solid evidence for these terminal stages is much later, in the form of $\mathrm{ME}\langle(\mathrm{t}) \mathrm{ch}\rangle$ and $\langle\mathrm{y}\rangle$.

$$
\begin{aligned}
& {[\mathrm{c}]>[\mathrm{cj}]>[\mathrm{cç}]>[\mathrm{c}]\langle\mathrm{c}\rangle \text { OR }} \\
& {[\mathrm{c}]>[\mathrm{cj}]>[\mathrm{tj}]>[\mathrm{t} f]\langle\mathrm{c}>9} \\
& {[\mathrm{f}]>[\mathrm{fj}]>\left([\mathrm{j}]^{10}>\right)[\mathrm{j}]\langle\mathrm{g}\rangle}
\end{aligned}
$$

Thus, the velar stops seem to have gone through processes of 'lenition' (cf. Minkova 2016: 56), in addition to palatalisation and potentially other types of assimilation. 'Lenition' is a somewhat contentious concept and is traditionally defined as change which involves weakening of segmental strength, such as opening or sonorisation (Honeybone 2002: 39-43), along typical scales, as in (2). ${ }^{11}$

$$
\text { stop }>\text { affricate }>\text { fricative }>\text { approximant }>\text { vowel }
$$

When the Roman alphabet was adopted for the writing of English, the Insular hand was used, which means Irish (or British) scribes were probably involved. Alphabetic writing, runic or Roman, entails a broadly phonemic analysis, since the principle of alphabetic writing is that there is one letter for each distinctive/salient sound. This has interesting consequences for our interpretation of OE spelling: The various values which are assumed for $\langle\mathrm{c}\rangle$ ([t $\mathrm{t} / \mathrm{c}]$ in cirice 'church' and [k] in cyning 'king') and <g> ([j] in giet 'yet', [y] in dagum 'days' and [g] in geminates) must either (a) have been perceived as so similar that they could be represented by the same letter, or (b) have been understood as allophonic variants in complementary distribution - or indeed both.

That the Anglo-Saxons learned their Roman script from Irishmen raises another question: What values did $\langle\mathrm{c}\rangle$ and $\langle\mathrm{g}\rangle$ have in Old Irish (OIr) at the time? Thurneysen (1961) states that $\langle\mathrm{c}\rangle$ corresponded to $[\mathrm{k}]$ or $[\mathrm{g}],{ }^{12}$ and $\langle\mathrm{g}\rangle$ had the values $[\mathrm{y}]$ and $[\mathrm{g}]$. The digraph $\langle\mathrm{cg}\rangle$ is used very

\footnotetext{
${ }^{7}$ The spellings suggest that OHG may have had variable devoicing of this geminate (which is in evidence also in Old Frisian and Middle Low German).

${ }^{8}$ Scholars agree that an affricate [dz] had developed already in Pre-Old Frisian (Nielsen 2012: 67; Luick 1914-40: $\S 687$, Anm. 3); whether it was phonemic is of no relevance here.

${ }^{9}$ The changes in (1) are intended to indicate that the palatalised stop [c] probably developed a palatal glide, to [cj], which in turn may have either assimilated and fronted to [t $\int$ ] via [tj], or developed into a palatal fricative [ç]; both would be lenition processes involving a decrease in the obstruction from a plosive to an affricate or fricative. The first path $[\mathrm{c}]>[\mathrm{cj}]>[\mathrm{cç/tj/tç]}>[\mathrm{c}]$ is evinced in Standard Eastern Norwegian (Haugen 1976: 268-272; Sandøy 1991: 182); the second [c] > [cj] > [(t)tj] (> [tf]) in some western dialects of Norwegian (Papazian \& Helleland 2005: 3; Thorson 1973: 335; Voronkova 1981: 269); Haugen (1976: 268) explains the latter development as the merger between [cj] and pre-existing [tj], which could affricate and assibilate to [tç/t $\mathrm{f}]$. The same dialects of Norwegian which have $\left[(\mathrm{t}) \mathrm{tj} \sim \mathrm{t} \int\right]$ for the reflex of palatalised $* k$ have $[\mathrm{jj} \sim(\mathrm{d}) \mathrm{dj}]$ for the reflex of palatalised $* g$ (Haugen 1976: 271; Papazian \& Helleland 2005: 53). A similar development from a voiceless velar plosive to a sibilant is seen in Latin $k>\mathrm{Fr}[\mathrm{c}]>$ [t]] or [ts] > [J], [s] (Pope 1934: §§283-285, 291-292).

${ }^{10}$ IPA [j] is for the voiced palatal fricative.

${ }^{11}$ Lass \& Laing explain the process of lenition in some detail (2013: 98-99, n. 6).

${ }^{12}$ Old Irish had phonemic palatalisation, and it was the adjacent vowels which indicated in spelling whether the consonant was palatal or velar (Thurneysen 1961); for the purposes of this article, there is no need to elaborate this point.
} 
infrequently in OIr, but is an 'etymological' spelling, in e.g. <ecguisti> for <ecuisti> (eg-guisti) (Thurneysen 1961: 23). It is worth observing that OIr $\langle\mathrm{cg}\rangle$ is not tautosyllabic, but straddles morpheme boundaries, like the OE clusters in micgern, orceard. Thus, if OE spelling is informed by the spelling practice of OIr, the digraph $\langle\mathrm{cg}\rangle$ in OE may indicate a geminate [J] or $[\mathrm{gr}] /[\mathrm{JJ}]$ or $[\mathrm{Jj}]$, or even [J3], whence it assimilated later to $[\mathrm{d} 3] .{ }^{13}$ This in fact agrees both with the Gmc postulated $*_{-} g j$ - and the attested forms in the other early WGmc languages. However, the question is why Anglo-Saxon scribes would adopt a very rare OIr spelling only for this one consonant, and not for any others. Logically, recourse must be had to OIr only if no other reasonable account can be established; but see White (2017) for a different view of the relation between OIr and OE spelling. ${ }^{14}$

\section{Previous accounts of the likely sound value and development of $\mathrm{OE}<\mathrm{cg}>$}

This section examines previous accounts of the sound value and development of $\mathrm{OE}\langle\mathrm{cg}\rangle$ words; for comparison, the assumed development of palatalised $* k$ is sometimes included, although I do not believe that the developments towards the terminal values $/ \mathrm{t} / \mathrm{and} / \mathrm{d} z /$ were exactly parallel (cf. Lass 1994 and Minkova 2016). Part of the reason is that lenis fricatives were allophonic at best in the old Gmc languages, and their development into distinctive phonemes is generally late. Some structuralists do not like asymmetries in phoneme systems, but asymmetrical systems are not really rare; e.g. Norwegian and Swedish still do not have voiced fricative phonemes. ${ }^{15}$ The very fact that the two velar stops as a result of Pre-OE palatalisation produced sounds that differed in manner of articulation shows that they did not and need not develop along the same paths: $* k$ produced a palatal stop or fricative (ditch, leech), whereas $* g$ produced a palatal approximant [j] which eventually vocalised (day, dry; Minkova 2016: 38).

First, let us consider the OE spellings for <cg> words. Campbell (1959: 27) states that the oldest spelling found in these words is $\langle\mathrm{gg}\rangle$ (Épinal Glossary, late $7^{\text {th }}$ century), whereas the Moore Bede and the Corpus Glossary (both $8^{\text {th }}$ century) have $\langle\mathrm{cg}\rangle$, and the Erfurt Glossary (c. 800$850)$ has both. Other OE variants are $\langle\mathrm{cgc}\rangle,\langle\mathrm{cgg}\rangle,\langle\mathrm{cgg}\rangle,\langle\mathrm{gcg}\rangle,\langle\mathrm{ggc}\rangle,\langle\mathrm{gc}\rangle ;^{16}\langle\mathrm{cg}\rangle$ is also

\footnotetext{
${ }^{13}$ Minkova (2019: 165), example (11), offers a similar conclusion.

${ }^{14}$ White (2017: 7) represents voiced and voiceless palatal affricates as /j/ and /c/ (IPA/dz/ and /t $\mathrm{j} /$ ), respectively, and indicates length/gemination by doubling the symbol. He believes OE spelling is based on OIr spelling, and, more specifically, that $\mathrm{OE}<\mathrm{cg}>$ corresponded to $/ \mathrm{j}(\mathrm{j}) /(2017: 17)$, i.e. IPA [dz(dz)]; the affricate was either a singleton or a geminate intervocalically, and a singleton finally. White later states that Campbell is right in stating that $\langle\mathrm{cg}>$ is due to Irish influence, in that "Irish spelling uses post-vocalic $\langle\mathrm{c}\rangle$ to mean $/ \mathrm{g} /$. But this observation misses a much more important point: spellings of the mixed voice [...] type, including $<\mathrm{cg}>$, both 1) occur in the spelling of OI [...] and 2) actually make sense" (2017: 17). They make sense in that clusters such as $<\mathrm{pb}>$ and $\langle\mathrm{cg}\rangle$ are used to correspond to a voiced intervocalic plosive across morpheme boundaries in Irish (and OE $\langle\mathrm{cg}\rangle$ was often found at morpheme boundaries), because there was no other unambiguous orthographic means available. White explains that the scribes may have used this spelling device in OE because they heard two types of geminate /gg/, one velar and one palatal, and that they chose to use $\langle\mathrm{cg}>$ for the palatal geminate. However, a palatal geminate $/ \mathrm{gg} /$ is [J] , not [dzdz], and White states in the preceding that OIr uses the 'mixed voice' spelling $<\mathrm{cg}>$ to indicate a voiced plosive, again pointing to [f] or [g], not $\left[\mathrm{d}_{3}\left(\mathrm{~d}_{3}\right)\right]$. It is possible that White merely suggests that the principle of $<\mathrm{cg}>$ is based on Irish spelling with "a non-literal meaning" (2017: 17), but that $<\mathrm{cg}>$ in Irish and $<\mathrm{cg}\rangle$ in OE corresponded to different sounds. It still does not make perfect sense, however, since the principle behind OIr $\langle\mathrm{cg}>$ is to indicate a voiced plosive in intervocalic position, not to indicate an affricate.

${ }^{15}$ Nor does Modern German, in some accounts (Kohler 1990), but this is a contentious claim.

${ }^{16}$ Searches for these spellings in The Dictionary of Old English Web Corpus produce the following results (not counting cases where the clusters straddle a word (or morpheme) boundary): $\langle\mathrm{cgc}\rangle 24$ hits (21 in OE $\langle\mathrm{cg}\rangle$ words, 1 in OE stycce 'bit, piece', 1 in OE grêting 'greeting', and 1 in OE tyrning 'turning around'); $<$ gcg $>30$ hits (24 in $\mathrm{OE}<\mathrm{cg}>$ words, 1 in OE sprengan 'sprinkle', 1 in OE mengan 'mix, combine', 1 in OE sceawung 'spectacle', 1 in OE bacling 'backwards', 2 in a word of uncertain etymology); $<\mathrm{ccg}>16$ hits ( 15 in $\mathrm{OE}<\mathrm{cg}>$ words, 1 in $\mathrm{OE}$ areccan 'spread out'); <cgg> 146 hits (142 in OE <cg> words, 4 in words of uncertain etymologies); $<$ ggc $>3$ hits
} 
used for words with assumed OE [g:], such as DOG and SHAG. ${ }^{17}$ Waxenberger (2017) finds no $<\mathrm{cg}>$ words represented in the limited OE runic corpus, but OE runes sometimes distinguish between velar and palatal reflexes of Gmc $* k$ and $* g$ in initial position, but not so consistently as to make interpretation easy; still, this makes Campbell conclude that there was a clearly perceptible phonetic difference between their realisations (1959: 173, n.1).

The development of $\mathrm{OE}<\mathrm{ng}>$ in certain contexts may be relevant, as a similar development to $\mathrm{PDE} / \mathrm{d} z /$ is attested for OE $-n g$ in some words, like SINGE and CRINGE; $\langle\mathrm{cg}\rangle$ and $\langle\mathrm{gc}\rangle$ are also found in these. Campbell (1959: 174) suggests that it is the same process of palatalisation which affected simplex $* k$ and $* g$ that affected these clusters, including $\langle$ nk $>$ and $\langle$ ng $\rangle$, both medially and finally. Normally, however, the development of $\mathrm{OE}-n g$ is to PDE / $\mathrm{y} /$ (though it remains [yg] in W Midl dialects), but it is worth noting that there are $\mathrm{OE}\langle\mathrm{cg}\rangle$ or $\langle\mathrm{gc}\rangle$ in words with $\mathrm{PDE} / \mathrm{y} /$ also (e.g. $<$ pincg $>/<$ pingc $>$ THING, <cynincg $>/<$ cyningc $>$ KING in the Dictionary of Old English Web Corpus). ${ }^{18}$

Previous scholars may be roughly divided into two groups, i.e. those who think OE <cg> corresponded to [d3] from an early stage, and those who think an affricate was a later development. To the first group belong Sievers (1895 [1968]), Hempl (1899), Campbell (1959), Wetna (1988), Hogg (1992), and Lass (1994). To the other group belong Sweet (1888), Luick (1914-40), Wright \& Wright (1925, 1928), and Moulton (1954). Some of their arguments are worth considering in detail.

Sievers (1968: 143-155) thinks that the palatal and velar geminates originally were plosives; the velar geminate was found in words like dogga DOG, and the palatal geminate <cg> [JF] developed into [dz], which stage was reached in OE. The reason why Sievers postulates such an early date for [d] $]$ is found in early OE spellings for words like fetian, ortgeard and midgern, which originally had $[\mathrm{t} \# \mathrm{j}]$ and $[\mathrm{d} \# \mathrm{j}]$, but which are occasionally spelt $\langle\mathrm{cc}(\mathrm{e})\rangle$ and $\langle\mathrm{cg}\rangle$, respectively: "The palatal stops $\dot{\mathbf{c}}$ and $(\mathbf{c}) \dot{\mathbf{g}}$ became at a rather early period palatal fricatives, ${ }^{19}$ that is, sounds like Eng. ch and dg. This is shown by forms like orceard, fęccean [...], micgern' (1968: 146). On Sievers's interpretation, $\langle\mathrm{cg}>$ is thus a back spelling in these words. As the segments in ortgeard, midgern always had a (post-)alveolar first element, the reasoning is that $\langle\mathrm{cc}\rangle$ and $\langle\mathrm{cg}\rangle$ must have corresponded to [t $\left.\int\right]$ and [ $\left.\mathrm{d}_{3}\right]$ in all words in which the digraphs were used, after the appearance of the back spellings c. 900, with the exception of DOG and FROG words, whose spellings are sometimes <docge> and <frocge>. This is a non sequitur to which I will return. No intermediate stages are suggested: thus, $[J]\rangle$ [d3]. Sievers's textbook was published in 1895 , so he may well have been the first to suggest that $\langle\mathrm{cg}\rangle$ must correspond to [dz] even in OE, and the evidence for this claim is found in the occasional $\mathrm{OE}\langle\mathrm{cc}(\mathrm{e})\rangle$ and $\langle\mathrm{cg}\rangle$ for etymological $\langle\mathrm{t} \# \mathrm{~g}\rangle$ and $\langle\mathrm{d} \# \mathrm{~g}\rangle$.

Even though the other scholars in this group may disagree over details, they agree with Sievers that the occasional $\mathrm{OE}\langle\mathrm{cc}(\mathrm{e})\rangle$ and $\langle\mathrm{cg}\rangle$ in orchard, midgern entail the existence of $\mathrm{OE}$ affricates, and most of them believe the geminates were originally stops, before they affricated and assibilated between the seventh and ninth centuries (so Hempl 1899, Campbell 1959, Wełna 1888, Hogg 1992). Lass (1994), however, assumes that the geminates were fricatives; thus,

\footnotetext{
(all in OE <cg > words). Numbers for $\langle\mathrm{gc}\rangle$ (2123 hits) and $\langle\mathrm{cg}\rangle$ (7967 hits) are too high for all the examples to be examined, but in a high number of instances of $\langle\mathrm{gc}\rangle$, the consonants straddle word boundaries.

${ }^{17}$ The Dictionary of Old English Web Corpus has one <docgena>, two <doggene> and one <doggi-> for DOG. For FROG, it has three $\langle$ frocga(n) $>$ and five $<$ frogg- $>$ (as well as two $<$ frosc $>$ ).

$18 \mathrm{https} / / / \mathrm{www}$. doe.utoronto.ca/pages/index.html

${ }_{19}^{1}$ It is clear that Sievers thinks the development is to phonetic affricates, despite the use of the term 'fricatives'.
} 
$[\mathrm{YY}]>[\mathrm{JJ}]>[\mathrm{dd} 3]$ is the suggested development in the words in question, although this oddly involves the development of a velar fricative [8y] into a palatal plosive [J]].

As for the details, Hempl (1899: 375-383) indicates stages by which what we would now call distinctive features are changed one at a time, in a sequence of changes: velar stop [g] > palatal stop $[\mathrm{J}]>$ palatal affricate [jj] > palatoalveolar affricate [d3]. Campbell (1959: 176) outlines the development $[\mathrm{g}]>[\mathrm{f}]>[\mathrm{di}]>[\mathrm{d} 3]$. He thinks the reflexes of Pre-OE $* g$ and $* k$ merged, at the $d i$ and $t i$ stage, with the reflexes of [d\#j] and [t\#j] in *midgern, fetian, ortgeard. Wetna (1986) suggests that the phoneme was /dzdz/, but seems to say (1986: 759) that the realisation was probably [ddz]/[d:3] (as it is difficult to pronounce two affricates, [dzdz], in a row, and [d:3] is the pronunciation of geminate affricates in other languages). This was simplified to [dz] wordfinally and medially after [n], but/dzdz/ was retained intervocalically (1986: 761). Hogg (1992: $\S \S 7.2-7.3,7.15-7.43)$ suggests the following paths for Pre-OE $* g$, as a singleton and as a geminate: ${ }^{20} * / \mathrm{\gamma} /[\mathrm{g}]>[\mathrm{f}]>[\mathrm{d} 3] ; * / \mathrm{\gamma y} /[\mathrm{gg}]>[\mathrm{fJ}]>[\mathrm{dd} 3]$. He seems to say that e.g. <licgan>lie had $[\mathrm{f}]$ in OE, i.e. a palatalised velar stop rather than a fricative or affricate (1992: $§ 7.15$ and fn. 3, §7.17 (3)), but it is not explicitly stated. As Lass (1994: 53-59) assumes a fricative [४У] in geminates in $\mathrm{OE}$, and thinks palatalisation and affrication and assibilation happened before $[\mathrm{\gamma}]>$

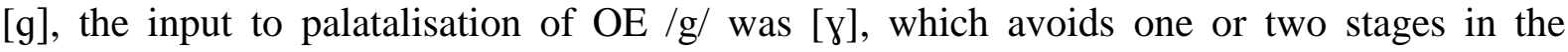
development of the voiced velar, because [y] goes straight to [j]. Hence, MIDGE had the development */muyja/ > [muyyja] > [mułfja] > [muddzja] > [myddzja] > [myddz].

In the other group, Sweet $(1888: \S \S 737,744,927)$ seems to think palatalised $* k$ had the value $[\mathrm{cc}]^{21}$ in $\mathrm{OE}$ and early ME, since <tch> spellings appear only sporadically, even in late ME. ${ }^{22}$ Sweet further believes the digraph $<\mathrm{cg}>$ had the value [э] in OE and eME (cf. Moulton 1954), and the present value [dz] (and [t $\mathrm{f}]$ ) was not reached until 'the First Modern Period', i.e. 15001600 , as shown by forms with $\langle\mathrm{d}\rangle$ and $\langle\mathrm{t}\rangle$. Words like nature, verdure provide a parallel, since they had ME [tj, dj], but in these it developed to [t $\left.\int, d_{3}\right]$. Sweet interestingly finds a parallel for this in [sj] > [J], but he does not refer to the identical earlier development of [tj, dj] in e.g. OE fetian, midgern to $\left[\mathrm{t} \int, \mathrm{d}_{3}\right]$. Sweet's suggested development is [gg] $>[\mathrm{JJ}]>\left[\mathrm{d}_{3}\right]$.

Luick (1914-40: §§631-633, 637, 640-645, 685-687, 690, 696), like Lass (1994), assumes [8у] > [gg] in geminates, but he thinks $* j$ was hardened to [gj] in emphatic styles, and that palatalised $* g$ became the same sound. The development was thus $[\mathrm{g}]>[\mathrm{gj}]>[\mathrm{dj}]>[\mathrm{d} 3]$, and the last stage took place in early ME. Due to paradigmatic variation and ON influence, Luick believes ME had both the velar stops and the palatalised/affricated consonant; $\mathrm{ME}\langle\mathrm{gg}\rangle$ is, however, deemed ambiguous, and Luick interestingly observes that $\langle\mathrm{cg}\rangle$ words are made to rhyme with one another only in ME (1914-40: $\$ 690$, Anm. 3). ${ }^{23}$ This fact suggests that <cg > corresponded to a consonant or consonant cluster unlike any other.

\footnotetext{
${ }^{20} \mathrm{Hogg}$ believes Pre-OE */y/ was [g(:)] initially, in geminates and after nasals (1992: §§7.2-7.3). He assumes that in the geminates */xx kk gg/, the cluster was ambisyllabic. "Therefore it has to be assumed that it is the second element which palatalized and that the first element assimilated to the second" (1992: $\$ 7.17$ (3)), i.e. regressive assimilation in at least two stages.

${ }^{21}$ Not [tj], as Penzl (1969: 102) infers.

${ }^{22}$ Jordan (1925: $\S \S 192$ ) states that $<\mathrm{dg}>$ is rare before the fifteenth century (cf. Wyld 1914: $§ 153$ (3)), but does not provide examples. A Linguistic Atlas of Late Mediaeval English (LALME) Vol. IV, p. 320b, lists 15 LPs containing $\langle\mathrm{tch}\rangle$, nearly all from Norfolk or Suffolk; this list may be defective, as $e L A L M E$ offers a few more $<\mathrm{tch}\rangle$ scattered across the country, but the main point to be made here is that they are infrequent even in late ME. ${ }^{23}$ But Luick believes Chaucer's rhyme brigge : Cantebrigge indicates [d3], whereas big 'large' : rig 'ridge, back' in Havelok (E Midl), and leggis : seggis in MS Laud 595 (W Midl) indicate [g] (1914-40: §690, Anm. 3).
} 
Wright \& Wright $(1925,1928)$ note that "there is no definite proof that" the "sound-change [to /d3/] took place in OE" (1925: 167); moreover, "Medial and final cg was a palatal explosive nearly like the g in N.E. get" (1925: 10). They do not think the back spelling <cc(e)> in words of the fetian, ortgeard type is sufficient evidence that [t $\left.\int\right]$ was reached in OE (1982: 163), but they believe the affricate developed in late OE or early ME (1928: 13-14, 127-128).

Table 3 summarises previous claims regarding the nature and development of the sound corresponding to $\mathrm{OE}\langle\mathrm{cg}\rangle$. Most of the OE grammars agree with Sievers (1895) that the development of [d3] was very early; the exceptions are Sweet (1888), Luick (1914-40) and Wright \& Wright (1928), who believe [d3] was reached at some point between early ME and 1600 .

Table 3. The development of palatalised $* g g$ according to the textbooks

\begin{tabular}{|c|c|c|c|c|c|c|c|c|}
\hline & WGmc & Anglo-Frisian & Pre-OE & $\mathrm{OE}$ & $1 \mathrm{OE}$ & eME & IME & eModE \\
\hline Sweet & $\mathrm{gg}$ & $\exists$ & & & & & & d3 \\
\hline Sievers & $\mathrm{gg}$ & $\exists$ & & $\mathrm{d}_{3}$ & & & & \\
\hline Hempl & $\mathrm{gg}$ & $\mathrm{I}(\mathrm{f})$ & $\mathrm{Jj}>\mathrm{d}_{3}$ & & & & & \\
\hline Luick & $\mathrm{gg}$ & $\mathrm{J}$ & $\exists \mathrm{j}$ & $\mathrm{dj}$ & & d3 & & \\
\hline Wright & $\mathrm{gg}$ & & $\exists$ & $\exists$ & $\mathrm{d}_{3}$ & d3 & & \\
\hline Jordan & $\mathrm{gg}$ & & & ? & d3 & & & \\
\hline Campbell & $\mathrm{gg}$ & $\exists$ & $\mathrm{di}$ & d3 & & & & \\
\hline Wełna & & & & dzdz & $\mathrm{dd}_{3}$ & & & \\
\hline Hogg & gg & $\mathrm{Az}$ & & dd3 & & & & \\
\hline Lass & 88 & $\mathrm{AJ}$ & dd 3 & & & & & \\
\hline
\end{tabular}

Minkova (2003, 2016, 2019) examines metrical and alliterative OE and ME data to determine the development of the Pre-OE velars in the history of English. She hypothesises that neither / $/ /$ nor $/ \mathrm{t} / /$ were phonemes until after $c .1000$ (2003: 71, 110), whereas the status of /dz/ or [dz] remains uncertain (2003: 134). However, phonetic affricates are indeed assumed for OE, certainly in the fetian, ortgeard set, and also for palatalised $* k$ in lenition positions, from the beginning of the ninth century (2003: 111). In her 2014 study, Minkova seems to think that the reflexes of the palatalised geminate $* k$ and $* g$ may have been phonetic affricates in OE (2014: $77,81,85-86$; but she also proposes $\left[\mathrm{c} / \mathrm{k}^{\mathrm{j}}\right]$ as possible realisations of the palatalised reflex of $k$ on pp. 81-82), and it is only in the most recent article that Minkova starts to question their existence, proposing other sequences in addition to [dz] and [dzdz] for the voiced geminate, i.e. [jj] and [dj] (2016: 49). Later, she states that in OE, "whatever $<\mathrm{cg}>$ represents phonetically, it is a sequence, or a geminate, not a phonemic singleton" (2019: 165). That is, Minkova is adamant that the sound sequences which were the reflexes of $\mathrm{OE}\langle\mathrm{cg}\rangle$ and palatalised $* k$, whatever their nature, remained bisegmental (having the weight of two consonants) far into the ME period, and did not become contour segments, i.e. true phonemic affricates with concomitant reduction of phonetic length and metrical weight, until then (2016: 51). The fact that it is only in late ME that alliterations between words with presumed initial [t $\mathrm{t}]$ (e.g. <charite> CHARITY) and words with initial /t/ (e.g. <teche> TEACH) start to appear (2016: 41) corroborates this conclusion. ${ }^{24}$

\footnotetext{
${ }^{24}$ The same 'evidence' is held against Minkova's hypothesis regarding the late phonemicisation of affricates as is invoked in the OE grammars: the occasional <cc(e)> and <cg> in fetian, ortgeard, midgern (Fulk 2003: 350; see also Laker 2003); these will be dealt with later.
} 
In other words, what is new in Minkova's model is (1) that there were no phonemic affricates in English until the eleventh century (which is in agreement with Luick, and Wright \& Wright), and (2) that $\mathrm{OE}<\mathrm{cg}>$ may not have corresponded to [dz], but to e.g. [dj] or [jj]. Additionally, Minkova suggests that incipient affrication occurred first in typical lenition positions, e.g. wordinternally in syllable codas, and in onsets of weakly stressed or unstressed syllables (2003: 110111). I will return to all of these issues, but in the next section, I will examine early ME spelling evidence which may throw some light on these topics.

\section{The LAEME material}

\subsection{Forms extracted}

ME spelling evidence has not hitherto been investigated systematically with a view to determining the sound correspondence(s) of $\mathrm{OE}\langle\mathrm{cg}\rangle$. As ME spellings have in fact been used to clarify other points of OE phonology (e.g. the three different correspondences of $\mathrm{OE}\langle\mathrm{g}\rangle$ ), I believe that such investigation should be undertaken: The ME reflexes of $\mathrm{OE}<\mathrm{cg}>$ may in fact shed light on the pronunciation of $\mathrm{OE}<\mathrm{cg}>$. For the present article, therefore, 1588 tokens were extracted from the $L A E M E$ corpus: ${ }^{25}$ all spellings for all nouns with $\mathrm{OE}<\mathrm{cg}>$ (91 tokens), and all spellings for those parts of the OE verbs BYCGAN, LECGAN, LICGAN, SECGAN, HYCGAN, PICGAN which had <cg> (1497 tokens); i.e. all forms in the present paradigm, except the 2.sg. and 3.sg. indicative, which had palatal singleton $\langle\mathrm{g}\rangle$, probably [j] (as did the preterite forms). Some of the verbs, e.g. OE BYCGAN, SECGAN and possibly HICGAN, had palatal singleton $\langle\mathrm{g}>$ in the imperative singular (i.e. byge, sege), but all forms for the imperative singular were extracted, as the rest of the verbs have $\mathrm{OE}<\mathrm{cg}>{ }^{26}$ Table 4 shows the paradigm for SECGAN, a class III weak verb (Sweet/Davis 1983: §74). Tables 5 and 6 show the numbers for LAEME types and tokens.

Table 4. The paradigm for OE SECGAN 'say'.

\begin{tabular}{|c|c|c|c|}
\hline SECGAN & & Present & Past \\
\hline \multirow[t]{4}{*}{ Indicative } & $1 \mathrm{sg}$. & secge & sǣgde \\
\hline & $2 \mathrm{sg}$. & sægst & sǣgdest \\
\hline & $3 \mathrm{sg}$. & sægp & s̄̄gde \\
\hline & $1-3 \mathrm{pl}$ & secgap & sǣgdon \\
\hline \multirow[t]{2}{*}{ Subjunctive } & $1-3 \mathrm{sg}$. & secge & sægde \\
\hline & $1-3 \mathrm{pl}$ & secgen & sægden \\
\hline \multirow[t]{2}{*}{ Imperative } & $2 \mathrm{sg}$. & sæge & - \\
\hline & $2 \mathrm{pl}$. & secgap & - \\
\hline Participle & & secgende & -s̄̄e $(g) d$ \\
\hline
\end{tabular}

\footnotetext{
${ }^{25}$ The $L A E M E$ corpus of tagged texts consists of entire early ME texts, or large extracts of long texts, each word of which has been tagged for lexico-grammatical information; the corpus covers all of England for the period $c$. 1150-1325. Each scribal text has been given an index number, to which I refer on occasion. See also http://www.lel.ed.ac.uk/ihd/laeme2/laeme2.html.

${ }^{26}$ All 82 tokens for -KNOWLEDGE, OE lëce 'physician', PARTRIDGE, JUDGE v., JUDGEMENT and EGG v. were collected for comparison. JUDGE, JUDGEMENT, EGG all have $\langle\mathrm{g}(\mathrm{g})\rangle$, except one form with $\langle$ hg $\rangle$ for EGG (\#160, 1275-99, Essex); JUDGE v. is $\langle\mathrm{iug}(\mathrm{g}) \mathrm{i}(\mathrm{e})\rangle$; it seems that the final $\langle\mathrm{i}\rangle$ indicates an assibilated $\langle\mathrm{g}\rangle$. KNOWLEDGE, $\mathrm{L} \overline{\mathrm{E} C E}$ mostly have $\langle\mathrm{ch}\rangle$, but there is a scattering of forms with $\langle\mathrm{g}\rangle$, which indicates assibilation/affrication of (French) $-g$ - before a front vowel, i.e. the beginning of lenited [dz] rather than etymological [t $\left.\int\right]$ in - LEDGE < OE -léace/-lēece; these are found in \#118 (1240-50, Cheshire) and \#295 (early $14^{\text {th }}$ century, West Riding, Yks), though in the latter, Old Norse influence and a velar stop may be in evidence. There are no tokens for OE MICGERN, nor for SINGE and CRINGE, in LAEME.
} 


\subsection{The nouns}

All the 91 tokens for reflexes of OE nouns with $\langle\mathrm{cg}\rangle{ }^{27}$ have $\langle\mathrm{g}(\mathrm{g})\rangle,{ }^{28}$ except four (Table 5). There is one <secg> for OE secg SEDGE in text \#173 (1200-50, Worcestershire), but the scribe in question (the archaising Tremulous Hand of Worcester) has $\langle\mathrm{g}(\mathrm{g})\rangle$ otherwise. There is one <ech3e> for OE ecg EDGE in \#273 (1225-49, Herefordshire), and two <suhge> for OE sucga in \#1100 (1275-99, Herefordshire). ${ }^{29}$ Of these, only <ech3e> may show assibilation and affrication, as <ch> may correspond to [t $\mathrm{f}]$, and the $<3>$ indicates a voiced segment, hence possibly [dz]. In the nouns, $\langle\mathrm{g}\rangle$ for $\mathrm{OE}\langle\mathrm{cg}\rangle$ in Northern ME (NME) texts could be from Old Norse (ON) and correspond to [g] (cf. Pak 1973), but as $\langle\mathrm{g}(\mathrm{g})>$ is found throughout the country, it is difficult to argue either way. ${ }^{30}$

Table 5. LAEME nouns with the reflex of OE $<\mathrm{cg}>$

\begin{tabular}{|c|c|c|}
\hline Lexeme & Nos. & Spellings \\
\hline BRIDGE & 20 & $20\langle\mathrm{gg}\rangle$ \\
\hline $\mathrm{EDGE}^{31}$ & 15 & $1\langle\mathrm{~g}\rangle, 13\langle\mathrm{gg}\rangle, 1<\mathrm{ch} 3\rangle$ \\
\hline HEDGE & 7 & $7<\mathrm{gg}>$ \\
\hline RIDGE & 36 & $23\langle\mathrm{~g}\rangle, 13\langle\mathrm{gg}\rangle$ \\
\hline SEDGE & 4 & $1<\mathrm{cg}\rangle, 1<\mathrm{g}\rangle, 2<\mathrm{gg}\rangle$ \\
\hline OE SECG 'man, hero, warrior' & 1 & $1<\mathrm{gg}\rangle$ \\
\hline OE SUCGA a type of bird & 4 & $2\langle\mathrm{gg}\rangle, 2\langle\mathrm{hg}\rangle$ \\
\hline OE TYGEBRYCG 'drawbridge' & 1 & $1<\mathrm{gg}\rangle$ \\
\hline WEDGE & 1 & $1<\mathrm{gg}\rangle$ \\
\hline OE WICG 'horse' & 2 & $2\langle\mathrm{~g}\rangle$ \\
\hline
\end{tabular}

\subsection{The verbs}

Of the 1497 tokens extracted from $L A E M E$ for verbs with $\mathrm{OE}<\mathrm{cg}>, 31 \%$ do not have a medial or final consonant, but rather $\langle\mathrm{ei}\rangle$ or $<\mathrm{ai}>$ (Table 6). It is thus very clear that the medial and final consonants had started to vocalise in the earliest ME (c. 1150). However, a retained consonant is also in evidence as late as 1340 (in LAEME text \#291, The Ayenbyte of Inwyt, and indeed in $L A L M E$ ), and up to the cut-off point for $L A E M E$ (around 1350), almost $70 \%$ of tokens still have a medial or final consonant. Forms which do have a medial consonant have $\langle\mathrm{g}(\mathrm{g})\rangle$, and there is not a single example of $\langle\mathrm{dg}\rangle$.

Table 6. $L A E M E$ verbs with the reflex $\mathrm{OE}<\mathrm{cg}>$

\begin{tabular}{|l|l|l|l|l|l|l|l|}
\hline VERB FORM & BUY & LAY & LIE & SAY & OTHER & TOTAL & VOC. \% \\
\hline Infinitive & $59(20)$ & $42(10)$ & $82(21)$ & $542(155)$ & $3(0)$ & $728(206)$ & 28.3 \\
\hline Imperative & - & $8(4)$ & $10(7)$ & $224(109)$ & - & $242(120)$ & 49.59 \\
\hline Gerund & $3(2)$ & - & $4(0)$ & $6(0)$ & $1(0)$ & $14(2)$ & 14.29 \\
\hline
\end{tabular}

\footnotetext{
${ }^{27}$ Most of the words with $<\mathrm{cg}>$ have variant spellings in OE, as stated in the beginning of section 3; OE $<\mathrm{cg}>$ is therefore not the unique input, but the fact that the nouns in question all have PDE / $3 /$ at least post facto indicates that they belong to one etymological group.

${ }^{28} \mathrm{As}\langle\mathrm{g}\rangle$ is counted MS $\langle\mathrm{g}\rangle,\langle\mathrm{z}\rangle$ and $\langle\mathrm{z}\rangle$.

${ }^{29}$ Besides, there is one <pertrich> for PARTRIDGE in \#174 (c. 1300, unlocalised language), but this word comes from OF pertriz, perdriz < Latin perdix, and so it is questionable as evidence for the ME pronunciation of the reflex of $\mathrm{OE}<\mathrm{cg}>$. OE SUCGA/SUGGA may belong to the same group as DOG, FROG, i.e. may have had a velar geminate.

${ }^{30}$ The different reflexes may only be known from their pronunciation in modern dialects, and paradigmatic alternation needs to be taken into account also, cf. Laker (2007).

${ }^{31}$ Including all derivatives in -edged.
} 


\begin{tabular}{|l|l|l|l|l|l|l|l|}
\hline Pres.ppl. & - & - & $8(1)$ & $4(2)$ & - & $12(3)$ & 25.0 \\
\hline Subj.pres.sing. & $1(1)$ & $6(1)$ & $19(1)$ & $104(34)$ & $1(0)$ & $131(37)$ & 28.24 \\
\hline Subj.pres.pl. & - & $1(0)$ & $2(2)$ & $16(5)$ & - & $19(7)$ & 36.84 \\
\hline 1.p.sg.pres.ind. & $1(0)$ & $1(0)$ & $6(0)$ & $136(47)$ & $2(0)$ & $146(47)$ & 32.19 \\
\hline Plural pres.ind. & $9(0)$ & $11(1)$ & $44(11)$ & $127(28)$ & - & $191(40)$ & 20.94 \\
\hline Polite pl. you & - & - & - & $1(1)$ & - & $1(1)$ & 100 \\
\hline Noun & $6(1)$ & $1(0)$ & - & $2(0)$ & - & $9(1)$ & 11.11 \\
\hline Adjective & - & $2(0)$ & - & $2(0)$ & - & $4(0)$ & 0 \\
\hline Total & $\mathbf{7 9 ( 2 4 )}$ & $\mathbf{7 2 ( 1 6 )}$ & $\mathbf{1 7 5}(\mathbf{4 3})$ & $\mathbf{1 1 6 4}(\mathbf{3 8 1})$ & $\mathbf{7 ( 0 )}$ & $\mathbf{1 4 9 7}(\mathbf{4 6 4})$ & $\mathbf{3 0 . 9 9}$ \\
\hline
\end{tabular}

In Table 6, the number of vocalised attestations for each verb part is given in parentheses after the total number of attestations for that part; the column OTHER includes OE HYCGAN and DICGAN. The right-most column shows the percentage of vocalised attestations of the total number of tokens for that verb part. It is clear that the imperative has more vocalised attestations than any other verb part, at almost $50 \%$, to which I will return.

Details regarding each verb are given in the following. For BUY and BUYER, there are 79 tokens in total, of which 55 have $\langle\mathrm{g}(\mathrm{g})\rangle(69.62 \%)$, and 24 do not have a medial consonant $(30.38 \%)$, as indicated in Table 7. The infinitive is recorded with more 'bare' forms (i.e. many different spellings, each of which lacks the medial consonant(s)) than any other verb part. Analogy with the 3. sg. pres. ind. may be responsible for the bare forms for the 3. sg. subj. The North and NE Midlands stand out as possible loci of change with regard to vocalisation.

Table 7. LAEME forms without a medial consonant for BUY and BUYER

\begin{tabular}{|c|c|c|c|c|}
\hline Text \# & Date & County & Part & Spellings \\
\hline 137 & $1275-99$ & Cambridgeshire & inf. & $1<$ bein> \\
\hline 2002 & $1275-99$ & Gloucestershire & inf. & $1<$ beye > \\
\hline 269 & $1275-1324$ & Norfolk & inf. & 1 <beyn> \\
\hline 179 & $1275-99$ & Unlocalised & inf. & $1<\mathrm{bi}\rangle$ \\
\hline 180 & $1275-99$ & Unlocalised & inf. & $1<$ bie $>$ \\
\hline 285 & $1300-24$ & Norfolk & inf. & 2 <beye>, 1 <byen> \\
\hline 296 & $1300-50$ & York & inf. & $1<\mathrm{bii}>$ \\
\hline 298 & $1300-50$ & $\begin{array}{l}\text { North Riding, } \\
\text { Yks }\end{array}$ & $\begin{array}{l}\text { inf. } \\
\text { v.n. }\end{array}$ & $\begin{array}{l}2<\text { bi }>, 2<\text { bie }>, 1<\text { by>, } 3<\text { bye }> \\
2<\text { biing }>\end{array}$ \\
\hline 169 & $1325-49$ & Lincolnshire & n. & 1 <byer> \\
\hline 295 & C14? & $\begin{array}{l}\text { West Riding, } \\
\text { Yks }\end{array}$ & $\begin{array}{l}\text { inf. } \\
\text { 3.sg.ps.sj. }\end{array}$ & $\begin{array}{l}1<\mathrm{bi}\rangle, 2\langle\mathrm{bij}\rangle \\
1<\mathrm{bii}\rangle\end{array}$ \\
\hline
\end{tabular}

For LAY, there are 72 tokens in total, of which 56 have $\langle\mathrm{g}(\mathrm{g})\rangle(77.78 \%)$, and 16 do not have a medial consonant $(22.22 \%)$, as indicated in Table $8 .{ }^{32}$ The infinitive and imperative have most attestations without a medial consonant, although there are such forms also for the 1. pl. pres. ind. and the 3. sg. pres. subj. The W Midlands stand out as loci of vocalisation, but the E Midlands and the North are also represented from the latter half of the thirteenth century.

Table 8. $L A E M E$ tokens without medial consonant for LAY

\begin{tabular}{|c|c|c|c|c|}
\hline Text \# & Date & County & Part & Spellings \\
\hline
\end{tabular}

\footnotetext{
${ }^{32}$ There is one form with $\langle\mathrm{gg}\rangle$ for palatal $\mathrm{OE}\langle\mathrm{g}\rangle$, which has not been counted among relevant forms; it is $\langle$ legget $\rangle$ 3.sg.pres.ind. in \#246 (1250-74, Herefordshire). It may be an analogical formation, the analogy being provided by the 1.sg.pres.ind., the present plural, and the infinitive, i.e. the present paradigm; the subject is the indefinite pronoun $m e$ 'one'. Of the other 14 tokens for the 3.sg.pres.ind. of LAY in LAEME, 13 have a diphthong followed directly by $\langle\mathrm{p}\rangle$, $\langle ð>$ or $\langle\mathrm{t}\rangle$, and 1 has the form <leigeð> (\#150, 1275-1299, Norfolk).
} 


\begin{tabular}{|c|c|c|c|c|}
\hline 64 & $1200-24$ & Essex & inf. & $1<$ leien> \\
\hline 247 & $1250-74$ & Herefordshire & imp. & $1<\mathrm{lei}\rangle$ \\
\hline 278 & $1250-74$ & Worcestershire & imp. & $1<$ leie > \\
\hline 280 & $1250-74$ & Wiltshire & imp. & $1<$ leie > \\
\hline 2002 & $1275-99$ & Gloucestershire & 3.sg.ps.sj. & $1<\mathrm{lei}>$ \\
\hline 282 & $1275-1324$ & Ely & inf. & $1<$ lein>, $1<$ leye > \\
\hline 1600 & $1275-1324$ & Oxfordshire & imp. & $1<$ leie $>$ \\
\hline 182 & c. 1300 & Lincolnshire & inf. & $2<$ leye $>$ \\
\hline 285 & $1300-24$ & Norfolk & inf. & $1<$ leyn> \\
\hline 296 & $1300-50$ & York & inf. & $2<$ <lai $>$ \\
\hline 297 & $1300-50$ & East Riding, Yks & $\begin{array}{l}\text { inf. } \\
\text { 1.pl.ps. }\end{array}$ & $\begin{array}{l}1 \text { <lai> } \\
1 \text { <lai> }\end{array}$ \\
\hline 298 & $1300-50$ & North Riding, Yks & inf. & $1<$ lai $>$ \\
\hline
\end{tabular}

Table 9. LAEME tokens without a medial consonant for LIE

\begin{tabular}{|c|c|c|c|c|}
\hline Text \# & Date & County & Part & Spellings \\
\hline 149 & 1154 & Peterborough & $\begin{array}{l}\text { inf. } \\
\text { 3.pl.ps. }\end{array}$ & $\begin{array}{l}1<\text { lien> } \\
1<\text { lien> }\end{array}$ \\
\hline 1200 & $1175-99$ & Essex & 3.pl.ps. & $1<\mathrm{li} \partial\rangle$ \\
\hline 1300 & $1175-99$ & Suffolk & 3.pl.ps. & $1<$ lið>, $1<$-lien $>$ \\
\hline 65 & $1200-24$ & Essex & 3.pl.ps. & $1\langle l i ð\rangle$ \\
\hline 246 & $1250-74$ & Herefordshire & imp. & $1<$ lie $>$ \\
\hline 247 & $1250-74$ & Herefordshire & $\begin{array}{l}\text { inf. } \\
\text { 3.pl.ps.sj. }\end{array}$ & $\begin{array}{l}1<\text { lie }> \\
1<\text { leie }>, 1<\text { lye }>\end{array}$ \\
\hline 160 & $1275-99$ & Essex & 3.pl.ps. & $1<$ lyen> \\
\hline 242 & $1275-99$ & Unlocalised & imp. & $1\langle\mathrm{li}\rangle$ \\
\hline 1100 & $1275-99$ & Herefordshire & imp. & $1<\mathrm{ly}\rangle$ \\
\hline 2002 & $1275-99$ & Gloucestershire & $\begin{array}{l}\text { imp. } \\
\text { 3.pl.ps. }\end{array}$ & $\begin{array}{l}3<\text { li }> \\
2<\text { lien }>\end{array}$ \\
\hline 282 & $1275-1324$ & Ely & inf. & $1\langle$ lien>, $2\langle$ lye $\rangle$ \\
\hline 159 & c. 1300 & Lincolnshire & $\begin{array}{l}\text { 3.sg.ps.sj. } \\
\text { 3.pl.ps. }\end{array}$ & $\begin{array}{l}1\langle\text { ly }> \\
1<\text { ys }>\end{array}$ \\
\hline 140 & $1300-24$ & Wiltshire & imp. & $1<-$ lie $>$ \\
\hline 155 & $1300-24$ & Norfolk & inf. & $1<\operatorname{lin}>$ \\
\hline 285 & $1300-24$ & Norfolk & inf. & $3<$ lye >, $1<$ lyen> \\
\hline 188 & $1300-50$ & Durham & inf. & $1<$ lie $>$ \\
\hline 257 & $1300-50$ & West Riding, Yks & ps.ppl. & $1<$ liande $>$ \\
\hline 296 & $1300-50$ & York & inf. & $2\langle$ lie $>, 1<-$ lie $>$ \\
\hline 297 & $1300-50$ & East Riding, Yks & inf. & $2\langle$ li $\rangle, 4\langle$ lie $\rangle, 1<-$ lie $\rangle$ \\
\hline 298 & $1300-50$ & North Riding, Yks & 3.pl.ps. & $1<$ lies>, 1 <lyes> \\
\hline
\end{tabular}

For LIE, there are 175 tokens in total, of which 132 have $\langle\mathrm{g}(\mathrm{g})>(75.43 \%)$, and 43 have no medial consonant $(24.57 \%)$, as indicated in Table $9 .{ }^{33}$ The infinitive and imperative are again attested with many tokens without a medial consonant, but so is the 3. pl. pres. ind. There are a few also for the 3. pl. pres. subj., the 3. sg. pres. subj., and the present participle. Vocalisation of the consonant had spread earlier to more verb parts for LICGAN than for the other verbs in this group, and the E Midlands seem to have been affected earlier than the rest of the country.

\footnotetext{
${ }^{33}$ There are 2 forms with $\langle\mathrm{gg}\rangle$ for palatalised $\mathrm{OE}\langle\mathrm{g}\rangle$; these have not been counted. They are <liggest $\rangle$ 2.sg.pres.ind. in \#222 (1275-99, mixed language), and <liggeth> 3.sg.pres.ind. in \#285 (1300-24, Norfolk). These may be analogical forms, the analogy being the rest of the present paradigm.
} 
In the category OTHER, all 7 forms for OE HYCGAN, PICGAN have a medial consonant (100\%): 5 have $\langle\mathrm{g}(\mathrm{g})\rangle, 2$ have $\langle\mathrm{h}\rangle$, and 1 has $\langle\mathrm{cg}\rangle$; the texts have been localised to Cheshire, Worcestershire, Hampshire and Norfolk. ${ }^{34}$

For SAY, there are 1160 tokens in total; they are too numerous for all the spellings without a medial consonant to be included in a table here. There are 779 forms with $\langle\mathrm{g}(\mathrm{g})\rangle$ (including 7 $\langle\mathrm{cg}\rangle ; 67.16 \%$ ), and 381 forms without a medial consonant (32.84\%); the proportions of verb parts with and without a medial consonant are given in Table $10 .{ }^{35}$

Table 10. LAEME forms for SAY

\begin{tabular}{|l|l|l|}
\hline SAY & Tokens & Vocalised (\%) \\
\hline Infinitive & 542 & $155(28.6)$ \\
\hline Imperative & 224 & $109(48.66)$ \\
\hline Gerund & 6 & $0(0)$ \\
\hline Pres.ppl. & 4 & $2(50)$ \\
\hline Subj.pres. & 120 & $39(32.5)$ \\
\hline 1.p.sg.pres.ind. & 136 & $47(34.56)$ \\
\hline Plural pres.ind. & 127 & $28(22.05)$ \\
\hline Polite pl. you & 1 & $1(100)$ \\
\hline Total & $\mathbf{1 1 6 0}$ & $\mathbf{3 8 1}(\mathbf{3 2 . 8 4})$ \\
\hline
\end{tabular}

There are many intermediate forms, e.g. 〈saize> in \#249 (1250-74, Herefordshire) and <seyze> in \#282 (1275-1324, Ely), in which there is a medial consonant, but the preceding vowel seems to be diphthongal; these have obviously been counted as having a medial consonant. The intermediate forms indicate the course of change for SAY: A glide vowel developed between the vocoid and the palatal consonant corresponding to $\mathrm{OE}\langle\mathrm{cg}\rangle$, or the latter vocalised to $i$. For SAY, a high number of attestations have $<\mathrm{i}>$ for the stressed vowel; it is possible that this is the result of regressive palatalisation (caused by the palatal consonant).

The material for SAY points in the same direction as that for the other verbs: The infinitive and imperative were affected by vocalisation first, followed by the 1. sg. pres. ind. In one of the earliest E Midlands text, palatalized forms are in fact more numerous than forms with a retained consonant (\#1300, 1175-99, Suffolk). The same is true of \#118 (1225-49, Cheshire), and of Northern texts from 1300-50. This points to the E Midlands being the locus of the development examined here, although the $\mathrm{W}$ Midlands are well represented from quite an early date too; however, this may well be a concomitant of the fact that most early texts come from these areas.

In numerous texts, the scribe uses co-variants with and without a medial consonant, so variant pronunciations must have persisted for a long time, ${ }^{36}$ but it is obvious that complete vocalisation of the medial consonant corresponding to $\mathrm{OE}\langle\mathrm{cg}\rangle$ was well under way in the late twelfth

\footnotetext{
${ }^{34}$ There are 2 additional tokens, one for each of the verbs LODGE and DRUDGE, which have PDE /dz/, like the OE $<\mathrm{cg}>$ nouns. Both ME forms have a medial consonant; they are recorded in \#1400 (1275-99, Norfolk) and \#1800 (1225-49, Worcestershire). The etymologies of the two verbs makes their inclusion questionable: LODGE comes from OF loge, and DRUDGE has an uncertain history. They have therefore been excluded from the analysis.

${ }^{35}$ In addition, there is 1 token for 'unsaying' in \#291 (1340, Kent), 1 for 'unsayingly' in \#301 (1175-99, Lincolnshire), and 2 tokens for 'sayer', also in \#291; all 4 have a medial consonant. Thus, there are 1164 tokens altogether for SAY and related words. There is also one form with $\langle\mathrm{gg}\rangle$ for palatalised $\mathrm{OE}\langle\mathrm{g}\rangle$, which has not been included in the count; it is <suggep> 3sg.pres.ind. in \#2002 (1275-99, Gloucestershire).

${ }^{36}$ Consider for instance \#249 (Herefordshire, 1250-75), which has 3 tokens for the 1. sg. pres. ind.; the spellings are widely different and likely correspond to different pronunciations: 〈saize>, <sape>, <sige>.
} 
century, at least in the eastern part of the country. However, as noted before, a retained medial consonant is attested into late ME (LALME).

The infinitive and imperative singular were clearly vocalised early, but as noted, the imperative singular of bycgan and secgan had a palatalised consonant in OE, and these may have acted as a 'bridge' (i.e. an analogical model) in the vocalisation of the imperative singular of the other $\langle\mathrm{cg}\rangle$ verbs. Other forms which were vocalised early are the 3. pl. ind. and the 1. sg. ind. Obviously, the preterites are believed to have had [j] even in OE; it seems, therefore, that the process that affected the pronunciation of $\mathrm{OE}\langle\mathrm{cg}\rangle$ in verbs may have been one involving analogy and paradigmatic levelling rather than sound change as such. This seems also to be the standard position, but I will return to this point in section 4.6. It could also be that the set bycgan, licgan, lecgan, secgan developed in a parallel fashion, due likely to their similar phonetic makeup, as they belong to different classes (bycgan and lecgan are weak class 1, licgan is strong class 5, and secgan is weak class 3); the coherence of the set may be part of the larger picture, somewhat like the PDE spread of -ung/-unk in the past tense of verbs whose infinitives end in -ing/-ink. ${ }^{37}$

At the outset, I assumed that there was no significance in the use of a single $\langle\mathrm{g}\rangle$ vs. a double $\langle\mathrm{gg}\rangle$ in the eME texts; $\langle\mathrm{gg}\rangle$ is the dominant spelling by far. However, for the sake of the argument, I have counted occurrences of single $\langle\mathrm{g}\rangle$ separately. Of the nouns, only EDGE, RIDGE, SEDGE and OE WICG have a single $\langle\mathrm{g}>$, and a single consonant is in fact the dominant form for RIDGE and WICG ${ }^{38}$ which both have a close front vowel preceding the consonant. 27 single $<\mathrm{g}>$ are attested in East Anglia, Berkshire, and the W Midlands (Table 11).

Table 11. Incidence of $\langle\mathrm{g}>$ for $\mathrm{OE}<\mathrm{cg}>$ in nouns in $L A E M E$

\begin{tabular}{|l|l|l|l|l|l|}
\hline Text & County & Lexeme, nos. & Text & County & Lexeme, nos. \\
\hline 18 & Unlocalised & RIDGE 1 & 261 & Shropshire & RIDGE 1 \\
\hline 121 & Mixed & RIDGE 1 & 270 & Norfolk & RIDGE 1 \\
\hline 122 & Cheshire & RIDGE 1 & 277 & Worcestershire & RIDGE 1 \\
\hline 160 & Essex & RIDGE 1 & 285 & Norfolk & RIDGE 1 \\
\hline 173 & Worcestershire & EDGE 1, SEDGE 1 & 286 & Berkshire & RIDGE 7 \\
\hline 175 & Norfolk & RIDGE 1 & 1000 & Shropshire & RIDGE 1 \\
\hline 227 & Unlocalised & RIDGE 1 & 1300 & Suffolk & WICG 2 \\
\hline 246 & Herefordshire & RIDGE 3 & 2002 & Gloucestershire & RIDGE 1 \\
\hline 248 & Herefordshire & RIDGE 1 & \multicolumn{5}{|l|}{ Total: 27 <g> } & \\
\hline
\end{tabular}

There are a mere 85 single $<\mathrm{g}>$ for $\mathrm{OE}<\mathrm{cg}>$ verbs (out of 1497 tokens). ${ }^{39}$ The tokens with a single $\langle\mathrm{g}\rangle$ do not appear to pattern in any systematic way, neither regarding areas nor regarding verb parts; they constitute $5.68 \%$ of the extracted verb forms in LAEME (excluding three forms with $\langle\mathrm{p}\rangle$ or $\langle\mathrm{h}\rangle$ ), whereas forms with $\langle\mathrm{gg}\rangle$ constitute $94.12 \%$.

\subsection{The Orrmulum}

In this regard, there is one eME text whose author is outstanding, both in having devised his own spellings system and in being exceptionally consistent in its application. This is of course the Orrmulum. Orm has a system with three different-shaped $g$ 's, all used etymologically.

\footnotetext{
${ }^{37}$ I owe this observation to an anonymous reviewer.

${ }^{38}$ But there are only two tokens for WICG.

${ }^{39} 60$ tokens for SAY (in addition, there are two tokens with intervocalic single $\langle\mathrm{p}>$ and one with final single $<\mathrm{h}>$ ); 1 for BUYER (\#1200, Essex, 1175-99); 2 for BUY (\#228, not localised, 1250-99; \#2002, Gloucestershire, 1175-99); 2 for LAY (\#4, 1175-99, and \#64, 1200-24, both Essex); 1 for HYCGAN (\#304, Hampshire, 1200-24); 19 for LIE.
} 
(a) Insular $g\langle z\rangle$ indicates a palatal approximant or fricative $[\mathrm{j} / \mathrm{j}]$; the digraph $\left\langle z^{\mathrm{h}}\right\rangle$ seems to correspond to a fricative, perhaps retained $\mathrm{OE}[\mathrm{\gamma}] .^{40}$

(b) The flat-topped $\langle\mathrm{g}\rangle$ corresponds to a plosive [g].

(c) The Caroline $\langle\mathrm{g}\rangle$, new in vernacular usage, is used only and always in $\mathrm{OE}\langle\mathrm{cg}\rangle$ words.

This strongly indicates a different sound correspondence for the reflex of $\mathrm{OE}\langle\mathrm{cg}\rangle$ than for $\mathrm{OE}$ $\langle\mathrm{g}\rangle$, and it does not follow that it was [dz]: It would be very strange if Orm, whose hearing evidently was acute, had analysed it as [d3], but then failed to represent the palatoalveolar, or even more so, the palatal approximant/fricative, for which he regularly writes $\langle\xi\rangle$ elsewhere. Orm's consistent $<\mathrm{g}(\mathrm{g})>$ for $\mathrm{OE}<\mathrm{cg}>$ has a set of negative implications, that is, non-[d], non$[\mathrm{g}]$, non- $[\mathrm{y}]$, non-[j], and non-[dz]; the most economical assumption is that it corresponded to $[\mathrm{J}],{ }^{41}$ but it may also indicate something like [j] or [3]. Orm's spelling does not really allow for a bisegmental analysis of the type [j] , and phonemic length in consonants had by all accounts been lost at this stage anyway, but the reflex of [ృj] could be an exception, and [J] $/[\mathrm{jj}] /[33]$ may be intended. ${ }^{42}$

\subsection{LAEME spellings for Gmc * $k$ and * $g$}

For comparison, $L A E M E$ spellings for simplex palatalised $\mathrm{Gmc} * k$ and $* g$ have been considered. For palatalised $g,\langle\mathrm{~g}\rangle$-type spellings remain dominant in the period 1150-1350, but $\langle\mathrm{y}$ - $\rangle$ starts appearing $c$. 1200-1250. For palatalised $k,\langle\mathrm{c}\rangle,\langle\mathrm{k}\rangle$ and $\langle\mathrm{ch}\rangle$ are all frequent, but with clear regional preferences: $\langle\mathrm{k}\rangle \mid\langle\mathrm{c}\rangle$ are used in the North and NE Midlands, $\langle\mathrm{ch}\rangle$ in the South, West, and SE Midlands.

These patterns suggest that spirantisation and/or affrication of simplex Pre-OE $* k$ is in evidence in (early) ME, but not really in OE, counter to what is claimed in the textbooks, which always assume $\mathrm{OE}[\mathrm{j}]$ for palatalised $* g$ and $\mathrm{OE}\left[\mathrm{t} \int\right]$ for palatalised $* k$. In fact, there is no hard evidence for assibilation and affrication until early-ish Middle English, and then only for the voiceless consonant (cf. Wright \& Wright 1925: 163); for the voiced palatal geminate $g g$, there is no unambiguous evidence at all for a palatoalveolar affricate until the mid-fourteenth century, cf. section 5 .

\subsection{Word class, analogy, paradigmatic levelling, and position within the word}

There is no doubt that the two different developments are connected to word-class, in that the nouns have $\mathrm{PDE} / \mathrm{d} 3 /$, whereas the verbs have a diphthong corresponding to $\mathrm{OE}\langle\mathrm{cg}\rangle$; the difference is apparent from the earliest ME material. However, this may be no more than a reflection of the fact that the two classes had different phonological environments: the verbs were more susceptible to spread of vocalisation in the first place, because there was

\footnotetext{
${ }^{40}$ Orm seems to use $\left\langle z^{h}>\right.$ and $\left\langle z^{\text {h }}>\right.$ contrastively. $\left\langle z^{\text {h }}>\right.$ is very common and corresponds to a fricative, possibly

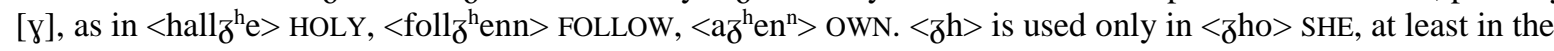
extract included in the LAEME Corpus of Tagged Texts, from which all the examples have been taken (http://www.lel.ed.ac.uk/ihd/laeme2/laeme2.html).

${ }^{41}$ Surely, someone (like Orm) who is capable of hearing and orthographically representing the difference between $[\mathrm{g}]$ and $[\mathrm{y}]$ and $[\mathrm{j}]$, which were all historically spelt $\langle\mathrm{g}\rangle$, is also able to hear the difference between $[\mathrm{g}]$ and $[\mathrm{g}]$ or $[\mathrm{j}] /[3]$ and indicate that difference orthographically.

${ }^{42}$ However, Minkova (2019: 168) states that the 'pre-affricates' were an intermediate category for Orm, as "intervocalically they are sufficient to render the stressed syllable heavy [...]. The weight of the stressed syllable [...] does not have to be attributed to the presence of a geminate: an assibilated, or a dental-fricative sequence will have the same effect".
} 
paradigmatic alternation between $\langle\mathrm{cg}\rangle$ and palatal $\langle\mathrm{g}\rangle$, whereas no such paradigmatic variation was found in the nouns.

As for position in the word, it is difficult to draw any certain conclusions, but the following points can be made. In hindsight we know that the infinitive was gradually reduced, starting with the loss of the final $-n$, then of the (now) final unstressed vowel, leaving what had been the medial consonant in final position. It could be that the consonant corresponding to $\mathrm{OE}\langle\mathrm{cg}\rangle$ was more susceptible to weakening word-medially, since the infinitive (which had a medial $\langle\mathrm{cg}\rangle$ in $\mathrm{OE}$ ) was affected by vocalisation very early; all other vocalised verb forms in LAEME had a word-medial consonant in OE, except the imperative singular, in which the consonant was word-final, as indeed it was in the nouns. However, word-medial position may be identical to syllable-final position, and Minkova in fact argues that "the palatalized velars became affricated first word-internally, where they could appear in coda position, a prototypical position of neutralization" (2003: 110).

The LAEME material shows somewhat diverging tendencies. The infinitive, which had a medial consonant in OE, accounts for $44.3 \%$ of all vocalised forms (and $28.3 \%$ of all infinitives show vocalisation). The imperative plural, which also had a medial consonant, however, shows the opposite tendency, with retention of the consonant in $94.6 \%$ of cases; the imperative singular, in which the consonant was word-final, shows vocalisation in $88.6 \%$ of the relevant forms (Table 12). The singular is by far the more frequent, which entails that on average, $49.6 \%$ of all imperatives show vocalisation.

Table 12. LAEME tokens for the imperative of LAY, LIE, SAY

\begin{tabular}{|l|l|l|l|}
\hline & Vocalised & Medial consonant & Total \\
\hline SAY & \multicolumn{1}{|l|}{} \\
\hline Imp. sing. & $104(88.89 \%)$ & $13(11.11 \%)$ & 117 \\
\hline Imp. pl. & $6(5.61 \%)$ & $101(94.31 \%)$ & 107 \\
\hline Total SAY & 224 \\
\hline LAY & $0(0 \%)$ & 4 \\
\hline Imp.sing. & $4(100 \%)$ & $4(100 \%)$ & 4 \\
\hline Imp.pl. & $0(0 \%)$ & 8 \\
\hline Total LAY & & \\
\hline LIE & $2(20 \%)$ & 10 \\
\hline Imp.sing. & $8(80 \%)$ & - & - \\
\hline Imp.pl. & - & 10 \\
\hline Total LIE & & 242 \\
\hline Total all verbs
\end{tabular}

It seems rather obvious that analogy played a role for the 1. singular present indicative, which may have vocalised by analogy with the rest of the singular paradigm; so also for the singular present subjunctive, which may have vocalised by analogy with the indicative. Early vocalised forms for the plural present indicative and plural subjunctive are more difficult to explain, but the analogy could have been through the 1 . singular $>1$. plural $>2 . / 3$. plural, although such a scenario remains speculative.

Maiwald (2017), who examines the vocalisation of the semivowels [j] and [w] and the voiced velar fricative $[\mathrm{y}]$ in $\mathrm{ME}$, concludes that the input consonant is "the most potent predictor for the sound change" (2017: 316), in that words with the reflexes of [j] show the highest frequency of vocalised spellings, whereas words with the reflexes of $[\gamma]$ show the lowest frequency of 
such forms. The other variables predicting vocalised spellings are (in decreasing order of importance): syllabicity (tautosyllabic semivowels show much higher frequencies of vocalised spellings), time (vocalised spellings increase in frequency over time), the quality of the preceding vowel (front monophthongs induce vocalisation of the following semi-vowel), dialect, and word class (2017: 316). Regarding word class, Maiwald finds that adjectives and adverbs have higher numbers of vocalised spellings than nouns, lexical verbs and quantifiers (2017: 269-270), and that nouns and lexical verbs alike show a steady increase in vocalised spellings in the course of eME (2017: 281). Maiwald also notes that "Verbs do not seem to show much of an increase of VOCALIC spelling proportions with lexel frequency" (2017: 276). ${ }^{43}$ Finally, he finds that open-class lexical items led the change (vocalisation), but that closedclass items "seem to have adopted the new spellings at a faster rate" (2017: 278). Variables which seem not to have affected vocalisation to any great degree are lexeme frequency, the quantity of the preceding vowel, and stress (2017: 317-318). For our purposes, Maiwald's most important finding is that tautosyllabicity is a highly significant predictor of vocalisation; besides, his observations that time and dialect correlate with vocalisation, whereas lexeme frequency does not, give some support to the findings reported here. In other words, we both find that spellings indicative of vocalisation increase in frequency with time, that parts of the E Midlands and SW Midlands led the vocalisation examined here.

\subsection{The $L A E M E$ evidence: summary}

We are now in a position to answer, at least tentatively, the four questions posed in the introductory section. (1) Are the ME spellings consistent enough, lexically and diachronically, or in individual texts, for any patterns to be detected? Yes, but in a negative way: eME spellings are very consistent, but it is the complete absence of $\langle\mathrm{d}-\rangle$ spellings for words with $\mathrm{OE}\langle\mathrm{cg}\rangle$ (and the absence of $\langle\mathrm{t}-\rangle$ forms for words with palatalised $* k$ ) which is most striking. (2) Is it possible to establish the likely OE and ME sound correspondences of <cg >? The orthographic evidence afforded by the Orrmulum precludes an affricate, as does the bulk of eME spellings, but this question will be answered in full in sections 5 and 6. (3) Had the diverging developments of nouns and verbs with $\mathrm{OE}\langle\mathrm{cg}\rangle$ started in the period investigated? The diverging developments had certainly started by 1150 , and may even have started in OE, but the process was not complete by 1350, which suggests that variant pronunciations persisted for a long time. (4) To what extent did the sound development of $\mathrm{OE}\langle\mathrm{cg}\rangle$ depend on word-class, position within the word, analogy and paradigmatic levelling? It is obvious that the differential treatments of the reflexes of $\mathrm{OE}<\mathrm{cg}>$ partly depended on the position of the sound in the word: The word-final consonant in the singular of nouns constituted the coda of a stressed syllable ${ }^{44}$ and was thus prevented from being vocalised and deleted, whereas the consonant was primarily found in word-medial (but syllable-final) position in the verbs and was more vulnerable to weakening and loss; this process was aided by the fact that $\langle\mathrm{cg}\rangle$ in verbs alternated with palatalised $g$ [j], which generally vocalised in other vocabulary as well. ${ }^{45}$ The importance of analogy with such forms cannot be overstated for the verbs.

\footnotetext{
${ }^{43}$ Maiwald states earlier that there seems to be a "positive correlation between FREQUENCY and "vocality" (2017: 261 ), in that there is a higher proportion of vocalic spellings for more frequent items, but he concludes that frequency has a "rather weak overall effect" (2017: 265).

${ }^{44}$ Plurals and genitives are a problem to this hypothesis, but non-tautosyllabicity vs. tautosyllabicity could play a role here. Maiwald finds that a distinction between ambisyllabic and heterosyllabic semivowels is unnecessary to explain their vocalisation; the crucial distinction is between tautosyllabic and non-tautosyllabic semivowels (2017: 217, 219-224, 317).

${ }^{45}$ Maiwald (2017) finds that the semivowels vocalised to a much greater extent when they were tautosyllabic with the preceding vowel, but he examines the semivowels and the voiced velar fricative, not primarily the reflex of $\mathrm{OE}<\mathrm{cg}>$.
} 
What is most striking about the $L A E M E$ data is the unusual and complete agreement among the scribes as to the spelling of the reflex of $\mathrm{OE}\langle\mathrm{cg}\rangle$ : They all use $\langle\mathrm{g}(\mathrm{g})\rangle$ in those cases where a consonant (letter) is retained, for nouns and verbs alike. Consequently, there are no regional patterns either, which again is rare for early ME. It implies (a) that all the scribes thought that the letter $\langle\mathrm{g}\rangle$ provided the best fit for the realisation of the reflex of $\mathrm{OE}\langle\mathrm{cg}\rangle$, and possibly (b) that this realisation, whatever its exact nature, may have been relatively uniform across the country (with the caveat that $\langle\mathrm{g}\rangle$ in the nouns in NME could show ON [g]). The existence of regional (allophonic) variation cannot be ruled out; all that is certain is that the ME spellings do not reflect such variation, unlike what is the case for the reflexes of palatalised singleton $* k$ and $* g$.

\section{The likely sound correspondence of $\mathrm{OE}\langle\mathrm{cg}\rangle$}

So far, we have primarily considered earlier accounts of the sound value of $\mathrm{OE}\langle\mathrm{cg}\rangle$, and we have seen that there is no direct evidence for the terminal stage [dz] in OE and ME. I do not believe that $\mathrm{OE}<\mathrm{cg}>$ was [dz], for the following five reasons.

1. OE words like frogga FROG and dogga DOG are also sometimes spelt with <cg> in OE (Luick 1914-40: §631; Campbell 1959: 27; Dictionary of Old English Web Corpus, see section 3, footnotes 13 and 14), yet these are always claimed to have a velar plosive [g:] in OE, and still do in PDE. Similarly, there are a fair number of minor spellings, e.g. $\langle\mathrm{cgc}\rangle,\langle\mathrm{ccg}\rangle$, $\langle\mathrm{gcg}\rangle$, mostly in $\mathrm{OE}\langle\mathrm{cg}\rangle$ words, but also for the final consonant of $\mathrm{OE}$-ing and -ung, for which PDE has $/ \mathrm{y} /(\mathrm{WMidl} / \mathrm{yg} /)$. This fact does not make sense if $\langle\mathrm{cg}\rangle$ corresponded to OE [d]], but it makes sense if $\langle\mathrm{cg}\rangle$ corresponded to a geminate plosive or a cluster containing a plosive.

2. The argument that $\langle\mathrm{cc}(\mathrm{e})\rangle$ and $\langle\mathrm{cg}\rangle$ must be [t $\mathrm{t}]$ and [dz] because earlier $\langle\mathrm{t} \# \mathrm{~g}\rangle$ and $\langle\mathrm{d} \# \mathrm{~g}\rangle$ are sometimes spelt $\langle\mathrm{cc}(\mathrm{e})\rangle$ and $\langle\mathrm{cg}\rangle$ is a non sequitur; they are rather attempts on the scribes' part to give orthophonic spellings for the new sounds $[\mathrm{tç}] /\left[\mathrm{t} \int\right]$ and $[\mathrm{dj}] /[\mathrm{d} 3]$ in ortgeard, fecc(e)an, micgern, developed from [t\#j] and [d\#j] across syllable and/or morpheme boundaries as a result of what is called 'YOD Coalescence' in the modern language (Wells 1982: 330-331); but it does not follow that $\langle\mathrm{cc}(\mathrm{e})\rangle$ and $\langle\mathrm{cg}\rangle$ must be [t]] and [d3] always (cf. Wright $\&$ Wright 1982: 163). True back spellings are bi-directional, but that is not the case with $\langle\mathrm{cc}(\mathrm{e})\rangle$ and $\langle\mathrm{cg}\rangle$ : Earlier $\langle\mathrm{t} \# \mathrm{~g}\rangle$ and $\langle\mathrm{d} \# \mathrm{~g}\rangle$ are sometimes spelt $\langle\mathrm{cc}(\mathrm{e})\rangle$ and $\langle\mathrm{cg}\rangle$, respectively, but etymological $\langle\mathrm{cc}(\mathrm{e})\rangle$ and $\langle\mathrm{cg}\rangle$ are never spelt $\langle\mathrm{tg}\rangle$ and $<\mathrm{dg}>$ in $\mathrm{OE}$. In fact, $\langle\mathrm{cg}>$ in micgern may equally indicate assimilation from $[\mathrm{d}+\mathrm{j}]$ to $[\mathrm{f}+\mathrm{j}]$ as a (post-)alveolar affricate; thus, if $\mathrm{OE}\langle\mathrm{cg}\rangle$ is [ $\mathrm{jj}]$, as argued below, the occasional $<$ micgern> makes perfect sense. Besides, syllable-initial consonant clusters may develop across morpheme boundaries although the same cluster is not found word-initially. ${ }^{46} \mathrm{~A}$ consonant cluster straddling a morpheme/syllable boundary is not of itself evidence that the same cluster occurs in free position. In essence, it means that the ortgeard, midgern words may have developed phonetic affricates, which could equally have been [tç] and [dj] as [t $\mathrm{t}$ ] and $\left[\mathrm{d}_{3}\right]$, and that the closest spellings in the established orthography, given the limitations of the Roman alphabet, were $\langle\mathrm{cc}(\mathrm{e})\rangle$ and $\langle\mathrm{cg}\rangle$. It does not follow that the palatalised reflexes of WGmc $* k$ and $* g$ had reached the assibilated stage in OE, although it cannot be stated with absolute certainty that assibilation was not present in OE either; all that is certain is that the realisation of $\mathrm{OE}<\mathrm{cg}>$ was not a singleton, but rather bisegmental, and that the first element was likely not dentalveolar.

\footnotetext{
${ }^{46}$ I owe this argument to Michael Benskin (pers.comm.).
} 
3. If $\langle\mathrm{cg}\rangle$ is indeed evidence of some kind of affricate, it need not be a palatoalveolar one, merely a palatal one, and affrication need not entail assibilation.

4. Unambiguous spelling evidence for palatoalveolar affricates, i.e. $\langle\mathrm{tch}\rangle$ and $\langle\mathrm{dg}\rangle$, is very late. The online MED (sub verbis) ${ }^{47}$ reports the following $\langle\mathrm{dg}\rangle$ and a few other irregular spellings for $\mathrm{OE}<\mathrm{cg}>$ words, the first of which does not appear until 1387 (Table 13).

Table 13. $<\mathrm{dg}>$ and other irregular forms for $\mathrm{OE}<\mathrm{cg}>$ words in the online MED.

\begin{tabular}{|l|l|l|l|}
\hline Lexeme & Date & Form & Source (online MED) \\
\hline BRIDGE & 1387 & brydge & Trev. Higd.(StJ-C H.1), 5.123 \\
\hline & 1450 & brydge & Treat.Fish.(Yale 171), 17 \\
\hline & $1480-81$ & Bridge & *CLRO MS Bridge House Rental 3, f. 333b \\
\hline EDGE & 1442 & edges & Invent.Gild in PSAL ser.2.5, 123 \\
\hline HEDGE & 1417 & hedge & Doc.in Sur.Soc.85, 12 \\
\hline & 1440 & hedgyn, hedge & PParv.(Hrl 221), 232 \\
\hline & 1440 & hedgydde & PParv.(Hrl 221), 494 \\
\hline & 1450 & hedgewoods & Chron.Repton, 70 \\
\hline & 1450 & hedgyng & Alph.Tales (Add 25719), 27/14 \\
\hline & 1475 & hedgys & Doc.in Bk.Brome (Brm), 138 \\
\hline MIDGE & 1500 & Hedgid & Lydg. CB (Lnsd 699), 49 \\
& 1500 & mydge (x2) & Rolle Psalter (UC 64), 104.29 \\
\hline RIDGE & $1340)$ & rigje & WBible(1) (Bod 959), 2 Kings 1.7 \\
\hline & $1445-6$ & Ridbandis & Acc.R.Dur.in Sur.Soc.99, 86 \\
\hline & 1470 & rydge & Malory Wks.(Win-C), 197/7 \\
\hline SEDGE & 1271 & Sechewyk & EPNSoc.6 (Sus.), 232 \\
\hline SLEDGE & 1399 & slechis & Mem.Ripon in Sur.Soc.81, 132 \\
\hline WEDGE & 1440 & $\begin{array}{l}\text { Wedge (x2), } \\
\text { wedge }\end{array}$ & PParv.(Hrl 221), 520 \\
\hline & $1448-9$ & wedgez & Acc.R.Dur.in Sur.Soc.99, 237 \\
\hline
\end{tabular}

5. It is likely that the developments of the voiced and voiceless sounds were not parallel, either in terms of dates, or of the phonetic stages involved: Given the Gmc absence of phonemic voiced fricatives in the early stages of the daughter languages, it is only to be expected that voiced fricatives and affricates should develop later than their voiceless counterparts, $\mathrm{cf}$. the first paragraph of section 3. Thus, evidence for [t $\left.\int\right]$ need not entail [dz].

To determine the likely sound correspondence of $\mathrm{OE}\langle\mathrm{cg}\rangle$, it is worth asking whether $\mathrm{OE}\langle\mathrm{cg}\rangle$ always corresponded to the same sound, given the diverging developments in nouns and verbs. Identity of sound in OE is indeed indicated by the scribes' choice of the same spelling for both parts of speech; etymology supports their analysis, as the words in question all stem from Gmc * $g j$. The next question then is which development 'continues' the OE sound, the nouns or the verbs? The answer must be that the nouns do, as the ME vocalisation of $\mathrm{OE}\langle\mathrm{cg}\rangle$ in verbs seems to be the result of analogy rather than of a sound change per se (though sound change

\footnotetext{
${ }^{47}$ The abbreviations for texts are those used by the online MED: https://quod.lib.umich.edu/m/middle-englishdictionary.
} 
cannot be ruled out): Palatal $\langle\mathrm{g}\rangle$ vocalises elsewhere too, e.g. in $\mathrm{OE}\langle\mathrm{weg}\rangle \mathrm{WAY}$ and $\langle\mathrm{d} g\rangle$ DAY (cf. late OE daei), and when it vocalised in those principal parts of $\mathrm{OE}<\mathrm{cg}>$ verbs which had palatal $\langle\mathrm{g}\rangle$ (generally those of the preterite paradigm), the non-palatal forms may also have developed variant forms with a vocalised consonant. As there is agreement (supported by the later developments) that $\mathrm{OE}\langle\mathrm{c}\rangle$ corresponded to $[\mathrm{k}]$ or $[\mathrm{t} / \mathrm{c}]$, and $\mathrm{OE}\langle\mathrm{g}\rangle$ corresponded to [g] or $[\mathrm{j}]$ or $[\gamma]$, depending on the phonetic context, the key to identifying the sound correspondence of $\mathrm{OE}<\mathrm{cg}>$ lies in just these allophones.

My simple suggestion is that $\mathrm{OE}<\mathrm{cg}>$ was pronounced $[\mathrm{J}(\mathrm{J}) \mathrm{j}],{ }^{48}$ that is, that $\mathrm{Gmc} *[\mathrm{\jmath j}]$ either was unchanged in (Pr)OE, or that the second element of the geminate later lenited to an approximant; this differs a little from Minkova's [ji] (2016: 49, and 2019: 164, example (9)). In the OE spelling system, $\langle\mathrm{g}>$ may unproblematically correspond to [j], and to indicate the different manner of articulation of the two segments, i.e. plosive vs. approximant, $\langle c\rangle$ was used for $[\mathrm{f}]$, as a plosive diacritic. The reason is partly that the Roman alphabet had only two letters for (historically) velar sounds of any kind, $\langle\mathrm{c}\rangle$ and $\langle\mathrm{g}\rangle$, and $\langle\mathrm{gg}\rangle$ more logically corresponded to a geminate velar plosive [g:] in words like frogga FROG than to a cluster [f(J)j], even if both $\langle\mathrm{cg}\rangle$ and $\langle\mathrm{gg}\rangle$ are used quite frequently in $\mathrm{OE}$ for both palatal and velar plosive geminates. My suggested pronunciation $[\mathrm{J}(\mathrm{J}) \mathrm{j}]$ agrees not only with the more certain phonetic realisations of Gmc * $g j$ in the other early Gmc languages, which all have [gj] or [jj], but also with the overwhelming body of spelling evidence for both $\mathrm{OE}$ and $\mathrm{ME}$, as well as with the later reflexes of the sound in question. It was noted earlier that $\mathrm{OE}\langle\mathrm{cg}\rangle$ alternates with palatalised $\langle\mathrm{g}\rangle$ in the verbal paradigms: It makes sense to have [j] (palatalised singleton) alternate with [jj] (palatalised geminate), but not with [dz], for reasons of phonetic similarity in two reflexes of what is etymologically the same sound; and it makes sense for this [jj], not [d3], to have become [j] in ME, whether by analogy with the preterite and other palatalised forms, or by a real sound change, i.e. true vocalisation of the kind [jj] $>[\mathrm{jj}]>[\mathrm{j}]>[\mathrm{i}]$.

The other spellings for $\langle\mathrm{cg}\rangle$ words in $\mathrm{OE}$ also make more sense if $\mathrm{OE}\langle\mathrm{cg}\rangle$ corresponded to $[\mathrm{f}(\mathrm{f}) \mathrm{j}] .<\mathrm{gg}\rangle$ is in fact the earliest spelling for $\langle\mathrm{cg}\rangle$ words (seventh century), but seems to have been 'reallocated' to [g:], which is logical, given the rationale behind alphabetic writing: A geminate sound should be represented by a geminated letter. It could also be that the phonetic similarity between a velar and a palatal plosive sometimes made scribes use $\langle\mathrm{gg}\rangle$ for both velar and palatal geminates without distinction - after all, the simplex velar and palatalised reflexes of Gmc $* k$ were clearly perceived as allophones for a very long time, given that they alliterate even in ME (Minkova 2016: 40). ${ }^{49}$ When $\langle\mathrm{cg}>$ started to be used for [f(J)j] a little later (eighth century), this may have been an attempt to reflect the difference between a palatal and a velar sound orthographically. Thus, <docga> could simply be a back spelling with the following rationale: If $\langle\mathrm{gg}\rangle$ may be used for both [g:] and [f:(j)], then $\langle\mathrm{cg}\rangle$ for [f:(j)] may be extended to the velar geminate also. Finally, if it is allowed that the $\langle\mathrm{c}\rangle$ in the $\langle\mathrm{cg}\rangle$ cluster represents [f], a spelling like <cynincg> or <cyningc ${ }^{50} \mathrm{KING}$ also makes sense: The last $\langle\mathrm{c}\rangle$ simply corresponds to a sound which is both a plosive and palato-velar, i.e. [J], after a palato-velar nasal, i.e. $[\mathrm{nJ}]$.

\footnotetext{
${ }^{48} \mathrm{OE}$ seems not to admit a cluster consisting of a tautosyllabic geminate+consonant, so [ృj] may not have persisted, but since the WGmc [j] causing gemination and palatalisation was not syllable-final, it could be that [j] remained

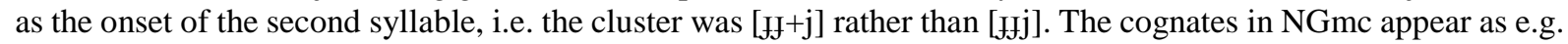
bryggja 'pier' (cognate with BRIDGE), liggja LIE, leggja LAY.

${ }^{49}$ Minkova (2016: 40) adduces clene Cudberte : cildhade in a text dated to $c$. 1100, and chiden : cnihtes; child : Claudiene; childes : quene from Lagamon's Brut (from the earlier manucscript Cotton Caligula A IX (C), "dated between 1189 and the first half of the thirteenth century" (2016: 50, fn. 48). Of course, this need not concern $<\mathrm{cg}>$, which is not found in initial position.

${ }^{50}$ The Dictionary of Old English Web Corpus has 164 attestations of <cynincg> and 190 of <cyningc>.
} 


\section{From OE $[\mathrm{J}(\mathrm{J}) \mathrm{j}]$ to late $\mathrm{ME} / \mathrm{d} \mathbf{z} /$}

It is common for clusters like [cj] and [jj] to coalesce or be dissimilated. ${ }^{51}$ Coalescent assimilation is observed in the NGmc palatal reflexes of Gmc $* k$ and $* g$, as indicated in (3) for Norwegian. Swedish and Danish went through exactly the same process, but in Danish, the process has been reversed (Sandøy 1991: 183; Papazian \& Helleland 2005: 53).

$$
\begin{aligned}
& \text { ON } g j>[\mathrm{jj}]>/ \mathrm{j} /(\text { gjøre 'to do', } \text { geit 'goat' with } / \mathrm{j}-/) \\
& \text { ON } k j>[\mathrm{cj}]>/ \text { ç/ (kjerne 'kernel, core', kinn 'cheek' with /ç-//) }
\end{aligned}
$$

In a process of dissimilation, the first element would become post-alveolar ([jj] $>[\mathrm{dj}]$ ), after which the second element would also become post-alveolar, in a process of assimilation $([\mathrm{dj}]>$ [dz]). Such a process is attested in Romance, in which [dz] had developed already in GalloRoman $\left(5^{\text {th }}-9^{\text {th }}\right.$ centuries $)$ from Latin $g$ and $j$, and was simplified to [3] in OFr in the thirteenth century, but remains in Italian (Pope 1934: $§ 1191-195,291-292) .{ }^{53}$ However, it seems as if the value [d3] was kept in early French loans in English, certainly in initial position in which the reflexes still have /dz/, whereas [3] is found in later loans in medial and final positions. What is clear is that the sound corresponding to $\mathrm{OE}\langle\mathrm{cg}\rangle$ fell in with this French [dz] in later ME, so even if $\mathrm{OE}\langle\mathrm{cg}>$ was not [dz] in $\mathrm{OE}$ or early ME, it had become similar enough to merge with it later. It is even possible that the realisation of the reflex of $\mathrm{OE}\langle\mathrm{cg}\rangle$ was affected by French [dz]: The realisation of the reflex of $\mathrm{OE}<\mathrm{cg}>$ was similar enough - perhaps $[\mathrm{dj}] /[\mathrm{dj}]$ by this stage - to French [dz] to merge with it, giving /dz/. The development of OE micgern, singe and of $\mathrm{PDE} / \mathrm{dj} />/ \mathrm{d} 3 /$ (as in due, did you) shows, however, that the last stage [dj] > [dz] may certainly also be an entirely native development. Minkova (2019) proposes an even closer link between the development of the affricates in English and French loans: The fact that $[\mathrm{t}]] /\left[\mathrm{d}_{3}\right]$ and $\left[\int\right] /[3]$ (both singletons) alternated in French may have provided "a structural parallel for the perception of the same native CC-sequences as singletons" (2019: 176).

In the larger picture, the development sketched out in the preceding entailed that $/ \mathrm{d}_{3} / \mathrm{became}$ a phoneme: it was no longer phonotactically restricted to initial position (French loans), but was now permitted in medial and final positions also. ${ }^{54} \mathrm{~A}$ relevant (inverse) parallel is seen in the fricatives, for which it is generally accepted that OE had voiced allophones in medial position, although they are not orthographically distinguished; these voiced fricative allophones were not phonemicised until ME, when French loans brought new words into the English vocabulary in which voiced fricatives were found in initial and final positions also. ${ }^{55}$ With the phonemicisation of voiced fricatives, and finally of $/ \mathrm{d} z /$, the consonant inventory of English had become symmetrical, in that the voiced-voiceless opposition found in the plosives was now also fully operative in the system of fricatives, with the exception of $/ \mathrm{h} /{ }^{56}$

\footnotetext{
${ }^{51}$ The reason may be that the two sounds are too similar to be retained as functionally separate sounds, cf. Guion (1998). Similar processes are observed in PDE, i.e. YOD Coalescence, in which /tj/ and /dj/ frequently become [t $\mathrm{f}]$ and [d]], both in syllable-initial position, as in Tuesday, due, and across word boundaries, as in hit you, did you (Wells 1982: 330-331).

${ }^{52}$ In fact, some dialects of Norwegian have [(t)tj/t $\left.\mathrm{f}\right]$ for the reflex of palatalised $\mathrm{Gmc} * k$, and some have [(d)dj] for the reflex of palatalised * $g$ (Thorson 1973: 337; Papazian \& Helleland 2005: 53); see also footnote 8.

${ }^{53}$ Similar though not identical cases of dissimilation are found in certain South-Western dialects of Norwegian, in which <ll> becomes [dl] and then in some cases [dd]; e.g. alle ALL > adle (> adde), cf. Haugen (1976: 274).

${ }^{54}$ This statement is purely descriptive: it is perfectly possible for phonemes to be phonotactically restricted and still be phonemes; $\mathrm{PDE} / 3 /$ is a case in point.

${ }^{55}$ Besides, initial fricatives were voiced in SW and SE dialects in ME (Wright \& Wright 1928: §236), the result of which is only occasionally seen in the standard language, e.g. vixen, vat. The consequences of this native development for the phonemicisation of voiced fricatives are uncertain and not directly relevant here.

${ }^{56}$ This is merely a statement of fact; I do not believe that phoneme systems need to be symmetrical.
} 
As for the date at which the terminal stage [dz] was reached, the element [d] must be late; otherwise, it is difficult to account for the two facts that (a) all eME scribes, including Orm, agree on $\langle\mathrm{g}(\mathrm{g})\rangle$, and (b) there is not a single $\langle\mathrm{d}\rangle$ in sight until $c .1340$, which is astonishing, especially for ME, even considering the power of spelling tradition. As we saw in section 3, previous scholarship has suggested different paths of development for the pre-affricates. In my opinion, the most likely path is given in (4a), and is based on OE and ME spellings and sound correspondences, as well as on knowledge of such processes cross-linguistically. (4b) is given to account for Orm's spellings. (4a) probably describes the simplest and most economical path of development from $\mathrm{OE}[\mathrm{f}(\mathrm{f}) \mathrm{j}]$ to late $\mathrm{ME}[\mathrm{d} 3]$.

$$
\begin{aligned}
& \text { a. }[\mathrm{\jmath jj}]>[\mathrm{jj}]>[\mathrm{dj}]>[\mathrm{d} 3] \text { OR } \\
& \text { b. }[\exists \mathrm{j}]>[\mathrm{jj}]>[\mathrm{jij}]>[33]>\left[\mathrm{d}_{3}\right]
\end{aligned}
$$

Typological arguments should be used with caution, as they are descriptive and not explanatory, but it might be noted even so that whereas phonemically opposed bilabial, alveolar and velar plosives are very common indeed, palatal plosives are rarer (Maddieson 1984: 32-33; Schmid 2011: 1762). ${ }^{57}$ The reason could be that a palatal plosive would have similar acoustic and perceptual properties to both alveolar and velar plosives (cf. Minkova 2016: 40, and references cited there), as their places of articulation are very close. Thus, a (pre-)palatal plosive may simply be reinterpreted as a (palato)alveolar plosive. In the case in question and as an alternative to a native development $[\mathrm{j} \mathrm{j}]>[\mathrm{dj}]$, it means that $[\mathrm{j} j]$ may have been reinterpreted or heard as [dj], which was sufficiently similar - as observed in hindsight - to fall in with [dz] in words of French origin. However, such a scenario hingeing on perceptual similarity and re-interpretation is hardly necessary to account for the development of $\mathrm{OE}\langle\mathrm{cg}\rangle$, as the articulatory route suggested in (4a) is perfectly adequate.

There are, however, a few analogical spellings in eME texts which may suggest that the affricate stage had been reached around 1250, as argued by Lass \& Laing (2013); their argument is worth detailed consideration, as it has consequences for what kinds of spellings we admit as 'evidence' for [d3]. Lass \& Laing state that "Caroline ' $g$ ' in Middle English is characteristically used for [g] or [dz] (usually non-initial) while surviving insular ' $z$ ' and its later development ' 3 ' are deployed for [j] and dorsal fricatives" (2013: 103). This statement appears not to hinge on the spelling system of Orm, who uses the Caroline $\langle\mathrm{g}\rangle$ only and always for the reflex of $\mathrm{OE}\langle\mathrm{cg}\rangle$, since they claim that "Any ' $g$ ' in LAEME [...] not combined in a ' $\mathrm{gh}$ ' cluster most characteristically represents a stop, with its next most common use being for [dz]" (2013: 103). Hence, it is clear that the authors believe Caroline $\langle\mathrm{g}>$ by itself may correspond to [dz] in early ME. Their most compelling evidence is found in the work of two early ME scribes, in the form of occasional spellings $<\mathrm{ig} / \mathrm{yg}>$ for ' $\mathrm{I}$ ', which are not taken as back spellings for [i:] in ME. The argument is that a few early ME texts have spellings which indicate devoicing of etymologically voiced stops, which leads to e.g. $\langle\mathrm{t}\rangle$ for etymological [d], and $\langle\mathrm{c}\rangle$ for [g]; it also leads to back

\footnotetext{
${ }^{57}$ Palatal plosives are found in $18.6 \%$ of the languages examined by Maddieson, whereas bilabial, dentalveolar and velar stops are found in, respectively, $99.1 \%, 99.7 \%$ and $99.4 \%$ of the languages of the world (Maddieson 1984: 32). In terms of sizes of stop systems by place, the majority of languages have three (53.9\%) or four (32.5\%) distinct places of articulation (1984: 31); if affricates are included, most languages make use of four (43.8\%) or five (27.4\%) distinct places of articulation for stops (1984: 34). That is, languages with a four-way system tend to have bilabial, dentalveolar and velar plosives, and palato-alveolar affricates. Moreover, 58 out of the 59 languages found to have palatal stops have four or more phonemically distinct places of articulation for stops; in other words, if a language has phonemically opposed palatal stops, it also has bilabial, dentalveolar and velar stops (1984: 33). Maddieson suggests that the three near-universal places bilabial, dentalveolar and velar are so common because they make use of three well-distinguished articulators - the lips, tongue tip or blade, and tongue body (1984: 32).
} 
spellings $\langle\mathrm{d}>$ for [t] and $\langle\mathrm{g}>$ for [k]. This is the case in one of the two texts (\#246, Hrf, 125075), ${ }^{58}$ and so <ig> may be for [ik] in the language of this scribe (2013: 109). The other text (\#263, Wlt, 1275-1300), ${ }^{59}$ on the other hand, has no $\langle\mathrm{c}\rangle$ or $\langle\mathrm{k}\rangle$ for [g] (i.e. no devoicing), but does have $\left\langle\mathrm{g}>\right.$ for $[\mathrm{k}]$ (e.g. $<$ penge $>$ THINK). ${ }^{60}$ As devoicing is not in evidence, the rationale for the back spellings is absent, and it is thus less likely that $\langle\mathrm{ig}\rangle \mid\langle\mathrm{yg}\rangle$ are back spelling for [ik] in this text (2013: 110). Four other forms in the same text, <wrege> WRETCHED, <vezge> FETCH, $<$ dregche> OE dreccan and <regche> OE reccan, in rhyming position, are interpreted as indicating [d3] for historical [t]] (2013: 110). \#246 also has some $\langle\mathrm{g}\rangle$ for etymological palatalised $* k(\mathrm{PDE} / \mathrm{t} / \mathrm{f})$, in e.g. <euerruge> EVEREACH and $<$ ginke $>$ "WHOOPING COUGH (cf. OE cincung BOISTEROUS LAUGHTER)" (2013: 111). Lass \& Laing therefore take $<$ ig $\rangle \mid\langle y g\rangle$ to represent [idz] < [itf], and to be examples of a "minor change of [t $\mathrm{t}]$ to [d3] in early Middle English, which continued into late Middle English at least in the word $\mathrm{CHURCH}$, but apparently did not last" (2013: 111). ${ }^{61}$

Lass \& Laing's interpretation seems logical, and the $\langle\mathrm{g}\rangle$ forms may thus consitute the best circumstantial evidence for the existence of at least a phonetic pre-affricate [dz] in the thirteenth century. However, their suggestion that there was a sound change involving the voicing of [t $\left.\int\right]$ need not entail that the $\mathrm{OE}<\mathrm{cg}>$ words also had [dz]: Phonetic voicing of [t $\left.\int\right]$ would necessarily give [dz], but that is not to say that etymological $\langle\mathrm{cg}\rangle$ words had [dz] at the time. Besides, it is uncertain whether [t $\left.\int\right]$ had been reached by this stage; it could equally have been [tj], which, if voiced, would become [dj]. The $\langle\mathrm{g}>$ spellings still need to be explained, and their origin must probably be sought in French, which used $\langle\mathrm{g}\rangle$ and $\langle\mathrm{j}\rangle$ for [d3]. Third, even if Lass \& Laing's assumption is correct, i.e. that $\langle\mathrm{ig} / \mathrm{yg}\rangle$ is unlikely for [ik] because there are no $\langle\mathrm{c} / \mathrm{k}\rangle$ for $[\mathrm{g}]$ in \#263, there is also a second interpretation: It could be that the final consonant of 'I' was voiced in unstressed position, giving <ig/yg>; voicing may be a type of lenition, and coda lenition/voicing is not unheard of in function words (e.g. in is, was, has, as). In fact, Lass \& Laing point out that \#263 has a few spellings like <fetd> FEET, <brytd> BRIGHT, <mytd> MIGHT, which to them "might suggest that original [ $\mathrm{t}]$ was perceived as having some degree of voicing, perhaps because of possible loss of aspiration" (2013: 110). Thus, what the spelling system of the scribe of \#263 may indicate is in fact more general voicing of etymologically voiceless stops in final position. If so, this also explains the <wrege>, <dregche>, <vezge> and <regche> for words with etymological [ $\mathrm{t}$ ] ( or its precursor): They simply indicate voicing of a stop consonant. Together with the one <ech3e> EDGE found in $L A E M E$, they may still indicate phonetic affricates $([\mathrm{tj}] /[\mathrm{tcc}] /[\mathrm{t} f]$ and $[\mathrm{dj}] /[\mathrm{dj}] /[\mathrm{d} z])$ in the mid-to-late thirteenth century in the $(\mathrm{S}) \mathrm{W}$ Midlands. Minkova concludes that "bisegmental perception and production of the pre-affricates $[\mathrm{t} f]$ and $[\mathrm{d} 3]$ is an option until at least the end of the fourteenth century" (2019: 178).

Lass \& Laing's most important claim, for our purposes at least, is that any Caroline $<\mathrm{g}>$ may correspond to [dz] by itself; to deal with this claim properly, all ME texts which use the Caroline $<\mathrm{g}>$ should be submitted to close analysis. That is, however, beyond the scope of the present article, but remains a topic to be explored in the future.

\section{Conclusions}

This article has argued that the traditional assumption that OE had full-blown phonemic affricates $/ \mathrm{d}_{3} /($ and $/ \mathrm{t} /$ ) for $\mathrm{OE}\langle\mathrm{cg}>$ (and $\langle\mathrm{cc}(\mathrm{e})>$ ) is wrong, in that the evidence for any such

\footnotetext{
${ }^{58}$ Cambridge, Trinity College B.14.39 (323), Hand A.

${ }^{59}$ London, British Library, Royal 2.F.viii, fol. 1v.

${ }^{60}$ LALME IV $321 \mathrm{~b}$ shows numerous $\left.<\mathrm{ng}\right\rangle$ for $\langle$ nk $\rangle$, and $\langle$ nk $>$ for $\langle$ ng $>$.

${ }^{61}$ But LALME IV 145a gives <cherge> and <chergys> CHURCH from Somerset and Essex, respectively, and 145b has <churge> in a source from Oxfordshire.
} 
in $\mathrm{OE}$ is conspicuously absent. The argument that occasional $\mathrm{OE}\langle\mathrm{cg}\rangle$ and $\langle\mathrm{cc}(\mathrm{e})\rangle$ for earlier $\langle\mathrm{d} \# \mathrm{~g}\rangle$ and $\langle\mathrm{t} \# \mathrm{~g}\rangle$ must imply that $\langle\mathrm{cg}\rangle$ and $\langle\mathrm{cc}(\mathrm{e})\rangle$ always correspond to affricates is tenuous at best, as true back spellings are bi-directional, which is not the case for $\langle\mathrm{cg}\rangle$ and $\langle\mathrm{cc}(\mathrm{e})\rangle$ : There is not a single $\langle\mathrm{d}-\rangle$-type or $\langle\mathrm{t}-\rangle$-type spelling for $\mathrm{OE}\langle\mathrm{cg}\rangle$ and $\langle\mathrm{cc}(\mathrm{e})\rangle$ in the entire corpus of $\mathrm{OE}$ and early ME texts. It is not until the fourteenth century that $\langle\mathrm{d}-\rangle$ and $\langle\mathrm{t}-\rangle$ for $\mathrm{OE}\langle\mathrm{cg}\rangle$ and $\langle\mathrm{cc}(\mathrm{e})\rangle$ make an entrance, and it is also in this period that words with assumed initial $[\mathrm{t} f]\langle\mathrm{ch}\rangle$ start to be used in alliteration with words with initial etymological $/ \mathrm{t} /\langle\mathrm{t}\rangle$ (Minkova 2016: 41).

My suggestion that $\mathrm{OE}\langle\mathrm{cg}\rangle$ corresponded to $[\mathrm{f}(\mathrm{f}) \mathrm{j}]$ agrees well with the assumed sound value of Gmc* $g(g) j$ in the other early Gmc languages, and with the spelling system of OE: $\langle c\rangle$ and $<\mathrm{g}>$ had a range of sound correspondences depending on context, which is a reflection of the fact that the Roman alphabet was not particularly well suited to represent the sounds of Gmc. Thus, $\langle\mathrm{gg}\rangle$ and $\langle\mathrm{cg}\rangle$ were both used for geminate velar/palatal plosives; eventually $\langle\mathrm{gg}\rangle$ was settled on for the velar geminate, which left $\langle\mathrm{cg}\rangle$ for the cluster with a geminate palatal plosive and an approximant, in which $\langle\mathrm{g}\rangle$ corresponds to [j], and $\langle\mathrm{c}\rangle$ is used like a plosive diacritic for [J] to indicate the different manner of articulation of the two sounds. The suggested [J(J)j] also makes sense with respect to the large body of $\mathrm{OE}$ and ME spellings, in which $\langle\mathrm{cg}\rangle$, and variants $\langle\mathrm{gc}\rangle,\langle\mathrm{cgc}\rangle,\langle\mathrm{cgg}\rangle,\langle\mathrm{gcg}\rangle,\langle\mathrm{gg}\rangle,\langle\mathrm{ggc}\rangle$ and $\langle\mathrm{cge}\rangle$ are used in $\mathrm{OE}$, and $\langle\mathrm{g}(\mathrm{g})\rangle$ reigns supreme in ME. Clearly, this shows that ME scribes found the letter $\langle\mathrm{g}\rangle$ to be the best fit for the realisation of the reflex of $\mathrm{OE}\langle\mathrm{cg}\rangle$, and it suggests that this realisation was relatively uniform across the country, although uniformity of spelling does not preclude realisational variability; usually in $\mathrm{ME}$, however, realisational variability is expressed through spelling variation.

I take Orm's use of Caroline $<\mathrm{g}>$ for $\mathrm{OE}<\mathrm{cg}>$ only (and always) to indicate that his phonetic realisation of $\mathrm{OE}<\mathrm{cg}>$ was different from those of the reflexes of singleton $\mathrm{Gmc} * g$, and was thus neither [g], nor [8], nor [j], and certainly not [dz]. It may have been [f] , [jj] or [33] (given that Orm's spellings do not really allow for a bisegmental analysis). As for the path of development from $\mathrm{OE}[\mathrm{J}(\mathrm{J}) \mathrm{j}]$ to late $\mathrm{ME}[\mathrm{d} 3]$, a process of dissimilation plus assimilation similar to that observed in Romance languages is most likely, i.e. [łj] > [dj] > [dz]. If Orm's spelling corresponded to $[\mathrm{JJ}]$, the same applies; if not, an alternative path $[\mathrm{Jj}]>[\mathrm{jj}]>[33]>\left[\mathrm{d}_{3}\right]$ is not entirely improbable.

The LAEME material has $\langle\mathrm{g}(\mathrm{g})\rangle$ for nouns, and either $\langle\mathrm{g}(\mathrm{g})\rangle$ or $\langle\mathrm{ei} / \mathrm{ai}\rangle$ for the verbs, which shows that the developments of the sound in the two lexical sets had started to split in the earliest ME. Vocalisation or levelling was under way c. 1150, and may have started in the South-East Midlands (Suffolk) and North-West (Cheshire). The only LAEME spelling that could indicate affrication and assibilation is $\left\langle\mathrm{ch}_{3}\right\rangle$ in EDGE, in a text whose language has been localised to Herefordshire (\#273, 1225-49). Lass \& Laing (2013) report a handful of $\langle\mathrm{g}\rangle$ for presumed [t $\int$ ] (also in $L A E M E$ ), which may indicate voicing to [dz] and which stem from the same period and area as the <ch3> form (i.e. the South-West Midlands of the mid-to-late thirteenth century); these provide possible evidence for phonetic affricates [t $\int$ ] and [dz]. Forms with $\langle\mathrm{d}\rangle$ in the words in question are first attested $c .1387$, and then in a few tokens in the fifteenth century $(M E D)$.

Finally, it seems likely that the affricate stage was reached earlier for the voiceless sound than for the reflex of $\mathrm{OE}\langle\mathrm{cg}\rangle$. The French-influenced $\langle\mathrm{ch}\rangle$ for the reflex of $\mathrm{OE}\langle\mathrm{cc}(\mathrm{e})\rangle$ in $\mathrm{ME}$ appears very early, and the $\langle\mathrm{h}\rangle$ seems to suggest a fricative realisation of the preceding consonant; indeed, <ch> remains the typical spelling for $/ \mathrm{t} / \mathrm{in}$ PDE. The story is different for 
the voiced consonant, for which $\langle\mathrm{dg}>$ makes an entrance only in the fourteenth century. It remains a possibility that the reflex of $\mathrm{OE}\langle\mathrm{cg}\rangle$ had indeed merged with that of French [d 3 ] at a slightly earlier stage, but that the spelling tradition for French [dz] prevented any unambiguous evidence from appearing until later. Phonemicisation of /dz/thus cannot have taken place earlier than the thirteenth century, and was quite possibly even later.

\section{References}

Campbell, Alistair. 1959. Old English Grammar. Oxford: Clarendon Press.

Davis, Norman (ed.). 1983 (9 $9^{\text {th }}$ ed.). Sweet's Anglo-Saxon Primer. Oxford: Clarendon Press.

The Dictionary of Old English Web Corpus, compiled by Antonette diPaolo Healey with John Price Wilkin and Xin Xiang. Toronto: Dictionary of Old English Project 2009.

URL address: https://www.doe.utoronto.ca/pages/index.html

Fulk, Robert D. 2003. Review of Minkova 2003. English Language and Linguistics 7(2): 347351.

Guion, Susan G. 1998. The role of perception in the sound change of velar palatalization. Phonetica 55: 18-52.

Haugen, Einar. 1976. The Scandinavian Languages: An introduction to their history. London: Faber \& Faber.

Hempl, George. 1899. Old English $\dot{C}, \dot{C} \dot{G}$, \&c. Anglia 1899 (22): 375-383.

Hogg, Richard M. 1992. A Grammar of Old English. Volume 1: Phonology. Oxford: WileyBlackwell.

Honeybone, P. 2002. Germanic Obstruent Lenition; some mutual implications of theoretical and historical phonology. PhD dissertation, University of Newcastle upon Tyne.

Jordan, Richard. 1925. Handbuch der Mittelenglischen Grammatik. Heidelberg: Carl Winter.

Kohler, Klaus J. 1990. German. Journal of the International Phonetic Association 20(1): 4850 .

Ladefoged, Peter and Ian Maddieson. 1996. The Sounds of the World's Languages. Oxford: Blackwell.

Laing, Meg. 2008. A Linguistic Atlas of Early Middle English. University of Edinburgh. URL address: http://www.lel.ed.ac.uk/ihd/laeme2/laeme2.html

Laker, Stephen. 2003. Review of Minkova 2003. LinguistList 14.2625. URL address: http://linguistlist.org/issues/14/14-2625.html

Laker, Stephen. 2007. Palatalization of velars: A major link of Old English and Old Frisian. In Rolf H. Bremmer Jr., Stephen Laker and Oebele Vries (eds.), Advances in Old Frisian Philology (Amsterdamer Beiträge zur älteren Germanistik 64), 165-184. Amsterdam: Rodopi.

Lass, Roger. 1994. Old English. A historical linguistic companion. Cambridge: Cambridge University Press.

Lass, Roger and Meg Laing. 2013. The early Middle English reflexes of Germanic *ik 'I': unpacking the changes. Folia Linguistica Historica 34(1): 93-114.

Luick, Karl. 1914-40. Historische Grammatik der englischen Sprache, Vol. I, Parts 1 \& 2. Oxford: Basil Blackwell.

Maddieson, Ian. 1984. Patterns of Sounds. Cambridge: Cambridge University Press.

Maiwald, Patrick. 2017. The Vocalization of Semivowels in Medieval English: A quantitative study. Giessen: Giessener Elektronische Bibliothek.

McIntosh, Angus, Michael Samuels and Michael Benskin. 1986. A Linguistic Atlas of Late Mediaeval English, Vols. I-IV. Aberdeen: Aberdeen University Press.

The Middle English Dictionary; URL address: https://quod.lib.umich.edu/m/med/

Minkova, Donka. 2003. Alliteration and sound change in Early English. Cambridge: Cambridge University Press. 
Minkova, Donka. 2014. A Historical Phonology of English. Edinburgh: Edinburgh University Press.

Minkova. Donka. 2016. From stop-fricative clusters to contour segments in Old English. In Don Chapman, Colette Moore and Miranda Wilcox (eds.), Studies in the History of the English Language VII, 29-59. Berlin and Boston: Walter de Gruyter.

Minkova, Donka. 2019. Examining the Evidence for Phonemic Affricates: ME / $\widehat{\mathrm{t}} / \mathrm{d} / \mathrm{d} \bar{\zeta} /$ or $[\mathrm{t}-$ J], [d-3]? In Rhona Alcorn, Joanna Kopaczyk, Bettelou Los and Benjamin Molineaux (eds.), Historical Dialectology in the Digital Age, 156-183. Edinburgh University Press.

Mitchell, Bruce and Fred C. Robinson. 1992 ( $5^{\text {th }}$ ed.). A Guide to Old English. Oxford: Blackwell.

Moulton, William G. 1954. The Stops and Spirants of Early Germanic. Language 30(1): 1-42.

Nielsen, Hans F. 2012. The Germanic roots of the Old English sound system. In Irén Heggedüs and Alexandra Fodor (eds.), Historical Linguistics 2010. Selected Papers from the Sixteenth International Conference on English Historical Linguistics (ICEHL 16), Pecs, 23-27 August 2010, 43-72. Amsterdam, Philadelphia: John Benjamins.

Oxford English Dictionary Online; URL address: www.oed.com

Pak, Tae-Jong. 1973. Position and Affrication in Northumbrian Old English. Neophilologus 57: 74-82.

Papazian, Erik and Botolv Helleland. 2005. Norsk talemål. Kristiansand: Høyskoleforlaget.

Penzl, Herbert. 1947. The phonemic split of Germanic $k$ in Old English. Language 23: 34-42.

Reprinted in Roger Lass (ed.), 1969. Approaches to English Historical Linguistics: an anthology; 97-107. New York: Holt, Rinehart and Winston. [Page references are to this edition.]

Pope, Mildred K. 1934. From Latin to Modern French with Especial Consideration of AngloNorman. Manchester: Manchester University Press.

Quirk, Randolph and C.L. Wrenn. 1989 (2 $2^{\text {nd }}$ ed.). An Old English Grammar. London, New York: Routledge.

Sandøy, Helge. 1991. Norsk dialektkunnskap. Oslo: Novus.

Schmid, Stephan. 2011. An Acoustic Analysis of Palatal Obstruents in Two Romance Varieties. Proceedings from the 17th International Congress of Phonetic Sciences, 1762-1765.

Sievers, Eduard. 1968 [trans. and ed. by Albert S. Cook]. An Old English Grammar. New York: Greenwood Press.

Stiles, Patrick. 2013. The Pan-West Germanic Isoglosses and the Sub-Relationships of West Germanic to Other Branches. NOWELE 66(1): 5-38.

Sweet, Henry. 1888. History of English Sounds. Oxford: Clarendon Press.

Thorson, Per. 1973. Om regressiv palatalisering av $g$ og $k$ i germansk, serleg i nordisk. In Olav T. Beito and Ingeborg Hoff (eds.), Frå norsk målføregranskning, 329-354. Oslo: Universitetsforlaget.

Thurneysen, Rudolf. 1946. A Grammar of Old Irish. [Translated by D. A. Binchy and Osborn Bergin.] Dublin: Dublin Institute for Advanced Studies.

Voronkova, Galina. 1981. Hvislelyder i norsk. In Ernst H. Jahr and Ove Lorentz (eds.), Fonologi/Phonology, 259-272. Oslo: Novus.

Waxenberger, Gaby. 2017. The development of the Old English fuporc. In Gaby Waxenberger, Hans Sauer and Kerstin Kazzazi (eds.), Von der Hieroglyphen zur Internetsprache: Das Verhältnis von Schrift, Laut und Sprache/From hieroglyphs to Internet language: The relation of script, sound and language, 211-247. Wiesbaden: Reichert.

Wells, John C. 1982. Accents of English. Cambridge: Cambridge University Press.

Wełna, Jerzy. 1986. The Old English digraph <cg > again. In Dieter Kastovsky and Aleksander Szwedek (eds.), Linguistics across Historical and Geographical Boundaries: Vol 1: 
Linguistic Theory and Historical Linguistics, 753-762. Berlin, New York, Amsterdam: Mouton de Gruyter.

White, David L. 2017. Irish Influence in the Consonantal Spellings of Old English. Anglica 26(2): 5-23.

Wright, Joseph and Elizabeth M. Wright. 1928 ( $2^{\text {nd }}$ ed.). An Elementary Middle English Grammar. Oxford: Oxford University Press.

Wright, Joseph and Elizabeth M. Wright. 1925 ( $3^{\text {rd }}$ ed.). Old English Grammar. Oxford: Oxford University Press.

Wyld, Henry C. 1914. A Short History of English. London: John Murray. 